SAN-1265-8

Distribution Category UC-92a

\title{
ANALYSIS OF FIVE-SPOT TRACER TESTS TO DETERMINE RESERVOIR LAYERING
}

\section{SUPRI-TR-8}

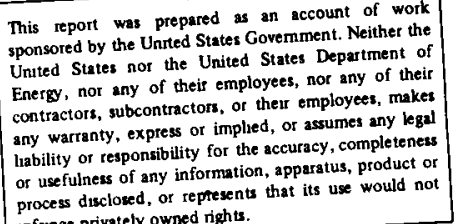

process disclored. or lepreshes.

by

Dexter L. Yuen, William E. Brigham and Heber Cinco-L Stanford University Petroleum Research Institute Stanford, California

Date Submitted-September 1978

Date Published-February 1979

Prepared for the U.S. Department of Energy

Under Contract No. E(04-3) 1265

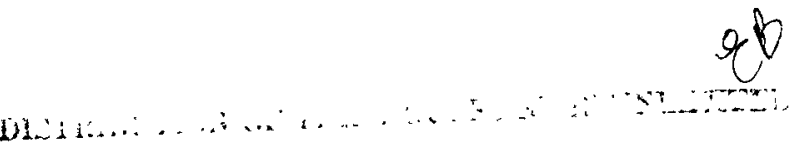




\section{DISCLAIMER}

This report was prepared as an account of work sponsored by an agency of the United States Government. Neither the United States Government nor any agency Thereof, nor any of their employees, makes any warranty, express or implied, or assumes any legal liability or responsibility for the accuracy, completeness, or usefulness of any information, apparatus, product, or process disclosed, or represents that its use would not infringe privately owned rights. Reference herein to any specific commercial product, process, or service by trade name, trademark, manufacturer, or otherwise does not necessarily constitute or imply its endorsement, recommendation, or favoring by the United States Government or any agency thereof. The views and opinions of authors expressed herein do not necessarily state or reflect those of the United States Government or any agency thereof. 


\section{DISCLAIMER}

Portions of this document may be illegible in electronic image products. Images are produced from the best available original document. 
ACKNOWLEDGEMENTS

This report was also submitted as a Master of Science degree report to the Petroleum Engineering Department of Stanford University by Dexter L. Yuen in August, 1978. 


\begin{abstract}
This report presents a computer algorithm for determining the degree of heterogeneity among the layers of a reservoir. The algorithm uses the equations developed by Brigham and $S_{m i}{ }^{1}$ that predict the behavior of a tracer slug flowing in a five-spot injection pattern.

To illustrate the use and potential problems in the application of this algorithm, examples are presented using five sets of simulated field test data. One example using actual field data is also presented.
\end{abstract}


TABLE OF CONTENTS

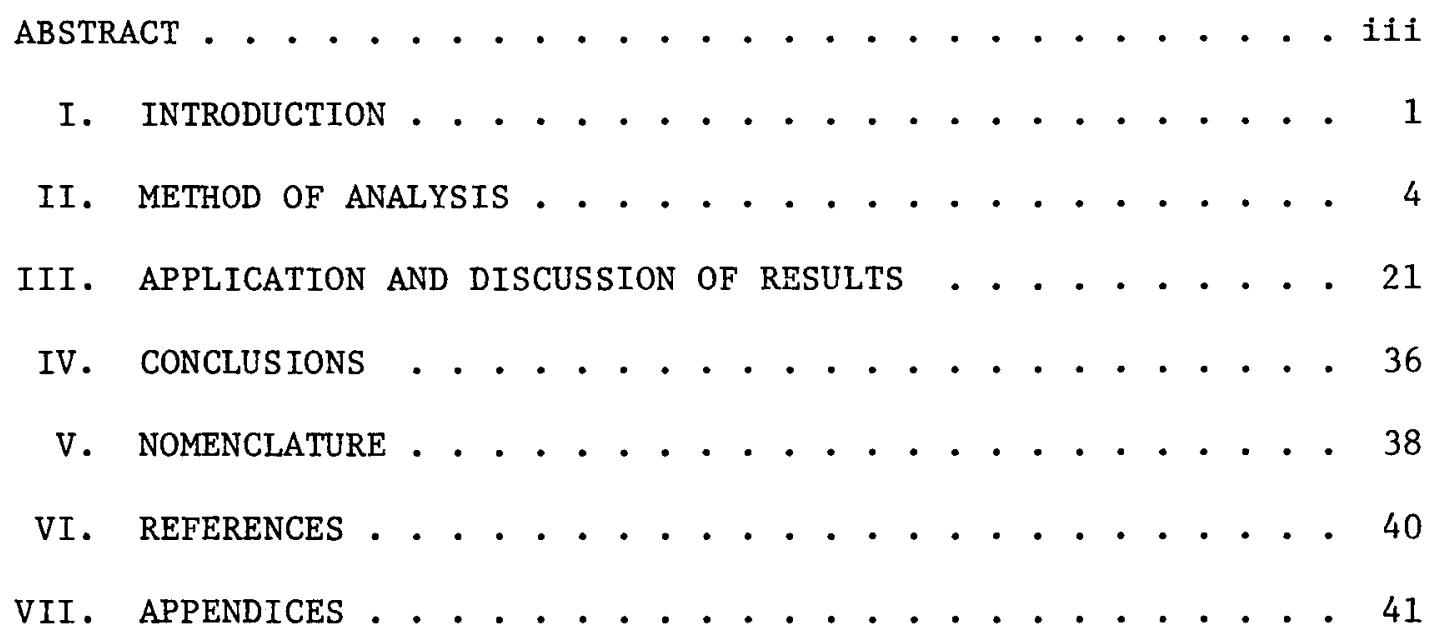




\section{LIST OF FIGURES}

1. DIMENSIONLESS SOLUTION FOR QUANTIFYING TRACER BEHAVIOR IN A FIVE-SPOT PATTERN . . . . . . . . . . . . . . . . . 8

2. DIMENSIONLESS SOLUTION FOR QUANTIFYING TRACER BEHAVIOR IN A FIVE-SPOT PATTERN . . . . . . . . . . . . . . . . 10

3. MULTI-LAYERED, FIVE-SPOT MODEL ASSUMED BY THE ALGORITHM . • 11

4. EMPIRICAL FIT TO RELATE L/ $\alpha$ WITH LOCATION OF PEAK IN DIMENSIONLESS SOLUTION . . . . . . . . . . . . 13

5. RESULTS OF ANALYZING DATA OF EXAMPLE $1 . \ldots . . . . . . . .23$

6. RESULTS OF ANALYZING DATA OF EXAMPLE 2 . . . . . . . . 24

7. RESULTS OF ANALYZING DATA OF EXAMPLE 3 . . . . . . . . 25

8. CONCENTRATION PROFILES FOR EXAMPLE 3 . . . . . . . . . 27

9. RESULTS OF ANALYZING DATA OF EXAMPLE 4 . . . . . . . . . 29

10. RESUltS OF ANALYZING DATA OF EXAMPLE 5 . . . . . . . . 30

11. ACTUAL FIELD DATA (AMMONIUM THIOCYANATE TRACER DATA FROM WELL D IN BRIGHAM AND SMITH'S PAPER [REF. 1]) . . . . . . 32 


\section{LIST OF TABLES}

I. DIMENSIONLESS SOLUTION FOR QUANTIFYING TRACER BEHAVIOR IN A FIVE-SPOT PATTERN . . . . . . . . . . . . . . . . . . 7

II. DIMENSIONLESS SOLUTION FOR QUANTIFYING TRACER BEHAVIOR IN A FIVE-SPOT PATTERN . . . . . . . . . . . . . . . . 9

III. RESULTS OF ANALYZING SIMULATED FIVE-SPOT TRACER TEST DATA DATA . . . . . . . . . . . . . . . . . . 22

IV. RESULTS OF ANALYZING ACTUAL FIELD DATA (WELL D AMMONIUM THIOCYANATE TRACER TEST DESCRIBED IN THE BRIGHAM AND SMITH PAPER [REF. 1]) . . . . . . . . . . . . . . 34 


\section{INTRODUCTION}

The use of well-to-we11 tracers to detect reservoir heterogeneities is growing in importance in industry. In any fluid injection project, high permeability streaks in the reservoir can channel a disproportionate share of the injected fluid. In waterfloods, such streaks decrease the vertical sweep efficiency of the flood and cause early breakthrough of water in the producing wells. The initial result is an increase in the operating costs to handle the extra water. More important1y, this can lead to a decrease in ultimate oil recovery as these added costs force stoppage of the project before flooding of all the reservoir layers is complete. In enhanced recovery projects that use polymers, surfactants, or micellar fluids, these streaks can dramatically boost costs by causing inefficient use of these expensive chemicals. Therefore, before starting any fluid injection project, it is important to determine the existence of reservoir heterogeneities that can cause channeling so that corrective actions can be taken. Field tests with well-to-well tracers and the proper analysis of the test data provide one possible means of making that determination.

0 . R. Wagner ${ }^{2}$ has presented a list of the specific types of information obtainable from well-to-well tracer tests. This list includes:

(1) volumetric sweep--the volume of fluid injected until breakthrough of tracer in the producer gives an indication of the sweep efficiency. A small volume would be indicative of a fracture or high permeability streak. 
(2) identification of offending injectors--by using different tracers in different injectors in the pattern, one can determine which injector is causing early breakthrough in specific producers.

(3) directional flow trend--again by using different tracers in different injectors, one can spot the preferential direction of flow from injectors to producers.

(4) delineation of flow barriers--the failure of a tracer to travel from an injector to a producer would indicate that a flow barrier exists between the two wells.

(5) relative velocities of injected fluids--if different fluids are tagged with different tracers and then injected down the same wel1, the arrival times of the different tracers at a producer would give an indication of the relative velocity of their respective fluids.

(6) evaluation of sweep improvement treatments--use of tracers before and after a treatment can give an indication of the effectiveness of the work.

D. E. Baldwin, Jr., ${ }^{3}$ developed a computer model to predict the produced concentration profile of a tracer as it moved through a five-spot pattern. He divided the five-spot pattern into a series of divergingconverging radial elements between the injector and the producer. Each element had an included angle of one degree. The flow rates in each element were adjusted so that the overall fractional flow behavior would match that of a five-spot pattern. He then derived the mathematical equations that described the dispersion of the tracer as it moved down each element. 


\section{$-3-$}

Raimondi et al. 4 presented an approximate solution of the dispersion problem for diverging radial flow. W. E. Brigham and D. H. Smith applied Raimondi's solution to a five-spot pattern. Brigham later revised this work to account for diverging-converging radial flow. Because these revisions were never published, Brigham and Smith's original paper has been included in this report as Appendix A, with handwritten revisions included. Tracer test data usually comes in the form (or can be put in the form) of "tracer concentration at the producing we11" versus "total volume of fluid injected into the pattern." Brigham and Smith's work provides a dimensionless solution to the problem of quantifying the behavior of tracer flowing in a single layer in a five-spot pattern. The algorithm presented in this paper applies this dimensionless, single-1ayer solution to field test data coming from real multi-layer reservoirs. 


\section{METHOD OF ANALYSIS}

Brigham and Smith derived an integral equation to relate the tracer concentration at the producing well to the volume of fluid injected into one layer.

$$
\frac{C}{C m p}(P V)=\int_{a}^{b} \frac{\mathrm{dF}_{D}}{\mathrm{dQ}_{i}} e^{-\frac{3 \mathrm{~L}^{-}\left(\mathrm{Q}_{i}-\mathrm{PV}\right)^{2}}{\pi^{2} \alpha}} \mathrm{dQ}_{i}
$$

where $\mathrm{C}=$ concentration measured in the producing well

Cmp = the layer's peak tracer concentration in the reservoir in the vicinity of the producing well

$\mathrm{PV}=$ displaceable pore volumes of fluid injected

$L=$ distance from the injector to the producer, $\mathrm{ft}$

$\alpha=$ dispersion constant defined as equal to $2 \pi \phi \mathrm{rK} / \mathrm{Q}$ in units of $\mathrm{ft}$

$\mathrm{F}_{\mathrm{D}}=$ fraction of injected fluid in the producing stream

$\mathrm{Q}_{i}=$ displaceable pore volume, a variable of integration in units of pore volume in Eq. 1

$\phi=$ porosity, fraction

$\mathrm{K}=$ dispersion coefficient, $\mathrm{ft}^{2} / \mathrm{sec}$

$\mathrm{Q}=$ volumetric injection rate, $\mathrm{ft} \mathrm{t}^{3} / \mathrm{sec}-\mathrm{ft}$

$r=$ distance away from injector, ft

$\mathrm{a}, \mathrm{b}=$ limits of integration that depend on the injection pattern used

It should be noted that the dispersion "constant," $\alpha$, is constant only if the dispersion coefficient, $\mathrm{K}$, is assumed to be proportional to fluid velocity. To show this, assume: 


$$
K=\text { velocity } \cdot \text { constant }
$$

Since

$$
\text { velocity }=\frac{Q h}{2 \pi r h \phi}=\frac{Q}{2 \pi r \phi}
$$

Then

$$
\mathrm{K}=\frac{\mathrm{Q}}{2 \pi r \phi} \cdot \text { constant }
$$

The dispersion "constant" can then be expressed as:

$$
\alpha=\frac{2 \pi \phi r \mathrm{~K}}{\mathrm{Q}}=\frac{2 \pi \phi \mathrm{r}}{\mathrm{Q}} \cdot \frac{\mathrm{Q}}{2 \pi r \phi} \cdot \text { constant }=\text { constant }
$$

For a five-spot pattern, Brigham and Smith empirically related $F_{D}$ and $Q_{i}$ by the equation:

$$
\begin{gathered}
\log \left[\log \left(\frac{1.07}{1.07-F_{D}}\right)\right]=-.0410+.581 \log \left(Q_{i}-.72\right) \\
\text { for } .72<Q_{i}<2.29
\end{gathered}
$$

Taking this equation, solving for $\mathrm{F}_{\mathrm{D}}$, and then differentiating with respect to $Q_{i}$ yields:

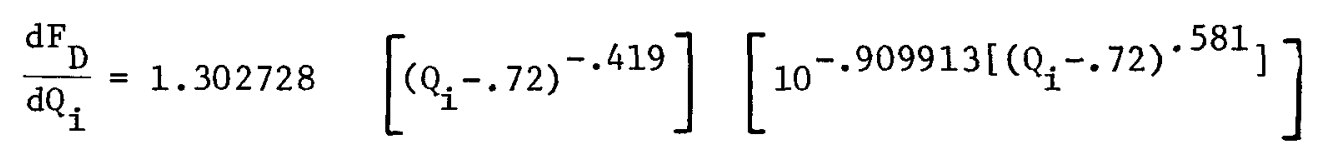

We can substitute Eq. 7 into Eq. 1 to get an expression applicable to a five-spot pattern:



$$
\begin{aligned}
& \exp -\left[\frac{3(Q i-P V)^{2}}{\pi^{2}} \frac{L}{\alpha}\right] d Q_{i}
\end{aligned}
$$




\section{$-6-$}

The results of solving Eq. 8 numerically are shown in Tables $I$ and II, and graphed on Figs. 1 and 2. Table II and Fig. 2 are included to show that they essentially match the hand-calculated numbers of $\mathrm{C} / \mathrm{Cmp}$ shown in Fig. 5 of Brigham and Smith's paper. The numbers in Tables I and II were calculated using an adaptive quadrature subroutine based on the eight-point Newton-Cotes integration formula.

To apply Brigham and Smith's solution, we make the same assumptions they did:

(1) the permeability and porosity are homogeneous within each layer,

(2) the dispersion coefficient, $\mathrm{K}$, is proportional to the velocity of the fluid (so that $\alpha$ is constant),

(3) the mobility ratio is one;

(4) the water saturation is constant in each layer.

We also make the following additional assumptions to apply this singlelayer solution to our multi-layer system:

(1) there is no crossflow between layers,

(2) the dispersion constant, $\alpha$, is the same for all layers,

(3) the distribution of fluid injected into each layer is proportional to the $\mathrm{kh}$ of each layer,

(4) the distribution of the tracer material is also proportional to the $\mathrm{kh}$ of each layer.

To develop the analysis algorithm for a multi-layer system, consider layer $j$ in our model (Fig. 3). If the injection rate into layer $j, i_{j}$, is proportional to $(\mathrm{kh})_{j}$, then 
TABLE I: DIMENSIONLESS SOLUTION FOR QUANTIFYING TRACER BEHAVIOR IN A FIVE-SPOT PATTERN

L/ALPHA=

PV

500.0

C/ Cmp

O. 500

0.510

0.530

0.540

0.550

0.563

0.570

0.580

0.590

0.500

0610

0.620
0.630

0.630

0.650

0.660

0.670

0.680

0.690

0.700

0.710

0.720

0.730

0.740

8.760

0.770

0.780
0.790

0.800

0.810

0.820

0.830

0.840

0.850

0.860

0.870

0.880

0.890

$0 \cdot 900$

0.910

0.930

0.940

0.940

0.950

0.960

0.970

- 980

9.990
1.000
0. $9747 E-04$

0.1916E-03

$0.3657 E-03$

$0.6776 e-03$

$0.1219=-02$

$0.2130=02$

$0.3615 c-02$

$0.5960 E-02$

$0.9542 E-02$

$0.1434 E-01$

$0.2244=-01$

$0.32965-01$

$0.4706 c-01$

$0.6533 E=04$

- $8819 e-42$

- 1158E 00

0.1480 c 00

-1840E 00

0 - 2229E 00

0.2631 E 00

$0.3027 E 00$

$0.3397 E$ OJ

$0.3724 E 00$

$0.3988=00$

$0.4180=00$

0.4291 E 00

$0.4321=03$

0.4277E

0.4277E 00

0.4158 00

0.40

- 3809E 00

J. 3588E CJ

- उ358E 0o

0.3129 L Uu

- 2909 E 00

$0.2704 E$ OD

0.2516 o 00

$0.2346=00$

$0.2195 E$ EO

$0.2060=00$

$0.1939=00$

$0.1832 E$ OO

$0.1736 E$ OJ

$0.1650 E$ OO

- 1572E 00

0.1572500

-1501E 0J

$0.1435=00$

0.1375000

- $1268=0$

$\begin{array}{lll}0.1268 C & 00 \\ 0.1220 E & 00\end{array}$
1000.0

$\mathrm{c} / \mathrm{Cmp}$

O. 7740 E-05

$0.2860 E-04$

C.5876E- 06

0.1 Y $22 E-05$

$0.6241 E-05$

U. 1861 E- 04

O. $5229 E-04$

U. $1385 E-03$

$0.3457 E-03$

C. 81 उ TEE-

O 1806 -O

O.1806E-02

O. $7472 E-02$

O. $472 E-02$

O. $394 E-01$

$0.2454 E-01$

$0.4084 E-01$

$0.6424 E-02$

$0.9560 E-01$

D.1347E OO

O.1800E DO

$0.228450 J$

$0.2755 E$ OO

O. $3168 E$ O

C. $3482 E$ OJ

$0.3668 E$ OO

$0.3721 E$ OO

3.3650 E

- 3484 E

- 3254 E DO

- J

- $2995 E$ OO

- $2733 E$ O

¿.2486E OO

O.2266E 00

O.2074E OO

0.1910E OO

C.1770E 0O

0.1650E OO

$0.1546 E$ OO

C.1455E OO

$0.1375 E 00$

0.1303E OO

$0.1238 E$ OO

U.1179 00

$0.1125 E 00$

:1125E

0.103 OE OO

$0.9879 E-01$

0. $9487 E-01$

C 9120 E- 1

$0.8778 E-01$
$0.8457 E-01$
5000.0

$\mathrm{C} / \mathrm{Cmp}$

10000.0

$\mathrm{C} / \mathrm{Cmp}$

$0.2146 E-30$

$0.1479 E-27$

$0.7517 E-25$

$0.7806 E-20$

$0.1594 E-17$

$3.2403 E-15$

$0.2672=-13$

$0.2103 \bar{\varepsilon}-11$

0.219 -1 1

$0.1328 E-09$

- 9 उ3E- 8

. $1956 E-06$

$0.4759=-05$

$0.3244 E-06$

$0.4556 E=05$

$0.4768 \equiv-04$

$0.3714 E-33$

$0.2258 \equiv-02$

$0.9384 E-02$

$0.3068 \mathrm{E}-01$

$0.7595 \equiv-01$

$0.1439 E$ JO

$0.2226 \equiv$ กी

$0.2516 E ~ J 0$

$0.2403 E$ OO

0.2199E OO

- L 8 AE 20

- 1 $548 E$ JO

O1561E ?o

- 2 OOE OO

0.1 $85=0$

$0.1085 E J 0$

$0.9915 E-01$

$0.9144=-01$

$0.8489 \bar{E}-01$

$0.7924 E-01$

$0.7429 \equiv-3$

$0.6992 E-01$

$0.6602 \equiv-01$

C. $6251 E-01$

$0.5934 E-3$

$0.5645 E-01$

$0.5381 \equiv-01$

$0.5138 \equiv-01$

$0.4914 \equiv-02$

$0.4707 E-01$

$0.4514 E-01$

$0.4336 E-01$

$0.4168 \equiv-31$

$0.4012=-01$

$0 \cdot 3865 E-01$
$0.2428 E-62$

$0.153 E-56$

0. $2979 E-51$

0 - $1192 E-46$

$0.1340 E-36$

$0.3044 \mathrm{~F}-32$

$0.1856 E-17$

0. 2018 E-17

- $1218 E-14$

$0.6752=-07$

$0.1080=-05$

$0.3362 E-C 4$

$0.57995-03$

C. 5579 E-02

$0.3029 E-01$

$0.9477 E-01$

C.2148E O?

- $1528 E$ O

0.1238E

$0.1054 E 00$

$0.9267 E-01$

$0.8309 E-03$

$0.7549 E-01$

$0.6926 E-C 1$

$0.5402 E-01$

$0.5953 \varepsilon-0 i$

0.5563 E-0?

0.5221 E-01

$0.4917 E-01$

$0.4645 E-01$

$0.4401 E-01$

$0.4179 E-01$

2. $3977 E-01$

0. 3792E-01

C. $3622 E-01$

$0.3320 E-0$ ?

$0.3185 E-01$

0. 2831 E-OL

$0.2728 E-01$
0.2631 E-01

50000.0

C/ Cmp

C. OODOE 00

$0.0000 E$ OO

0. DOOCE OO

0.0000 CO

0.0000 OO

C.000OE OO

- coode no

- co oor ó

0.000

- .0000 Do

- DOOOE 20

-. Co DOE OJ

- 0000 O

C.1875E-64

0.651 CE-52

$0.1083 E-40$

$0.2621 E-31$

$0.3283 E-22$

$0.5981 \mathrm{E}-15$

$0.5214 \mathrm{E}-0 \mathrm{~g}$

$0.2175 E-04$

$0.1035 E-03$

$0.1369 E-C 1$ 
FIG. DIMENSIONLESS SOLUTION FOR QUANTITYING TRACER BEHAVIOR IN A FIVE-SPOT PATTERNS

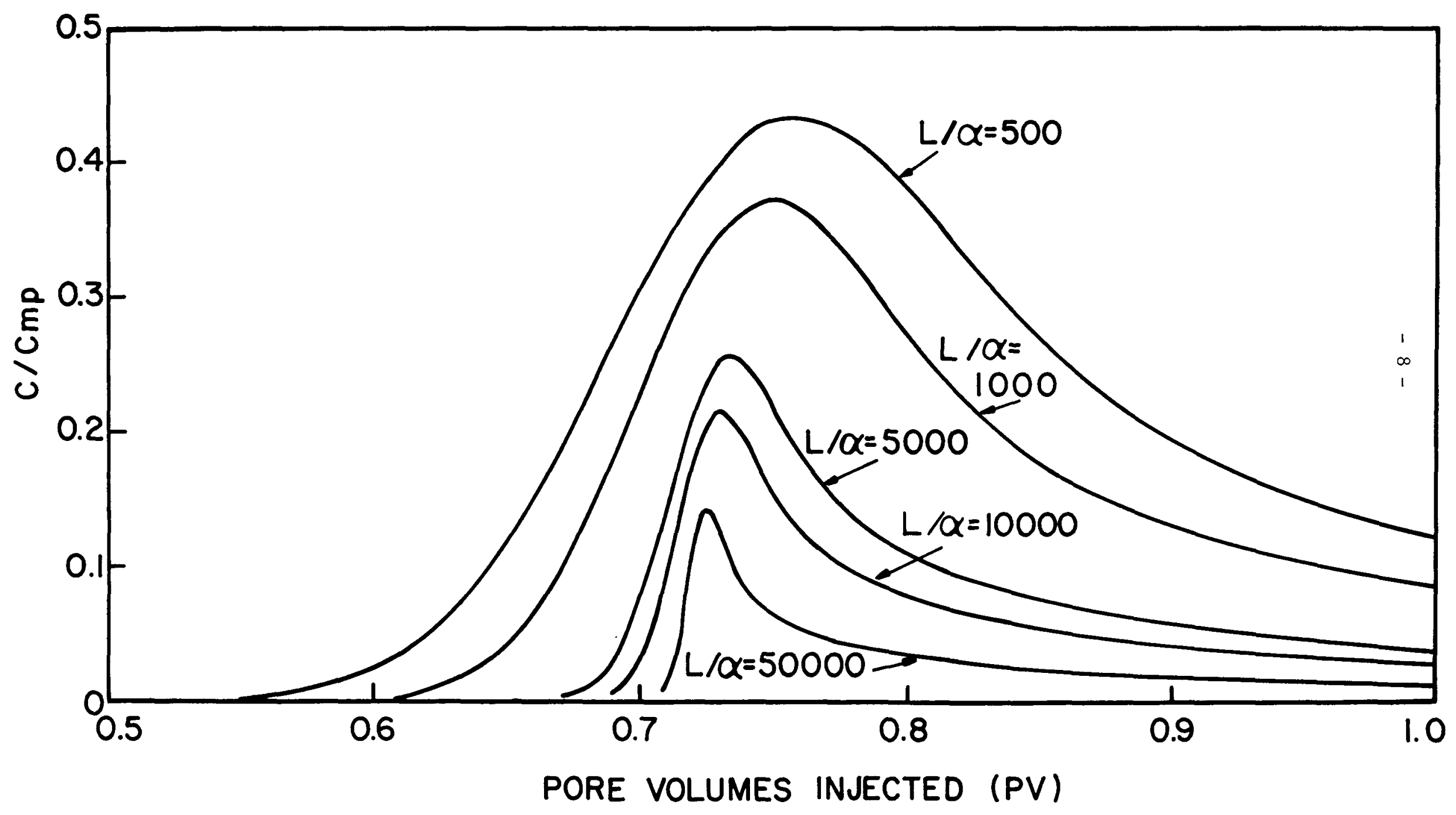


TABLE II: DIMENSIONLESS SOLUTION FOR QUANTIFYING TRACER BEHAVIOR IN A FIVE-SPOT PATTERN
$\mathrm{L} / \mathrm{ALPHA}=$
PV
417.0
$\mathrm{c} / \mathrm{Cmp}$
1250.0
$\mathrm{C} / \mathrm{Cmp}$
4170.0
$\mathrm{C} / \mathrm{Cmp}$
12500.0
$\mathrm{C} / \mathrm{Cmp}$

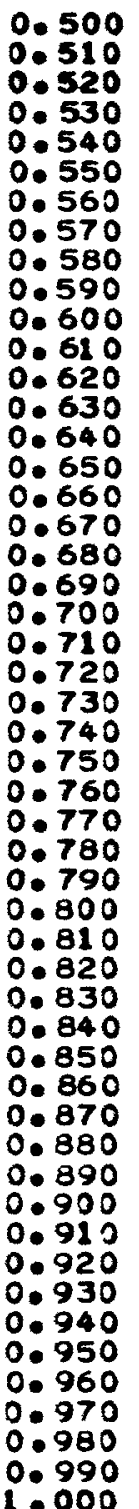

0.500

0.520

- 530

. 560

570

- 590

600

620

640

660

- 670

- 690

- 710

. 740

750

770

780

800

0.830

0.840

- 860

- 870

0.890

0.900

0.920

0.940

0.970

0.990

1.000
$0.3618 E-03$

$0.6378 \mathrm{E}-03$

$0.1841 E-02$

$0.3015 \bar{E}-02$

$0.4820 \mathrm{E}-02$

$0.7520=-02$

0.71

$01145 E-01$

$0.1703 E-01$

$0.3503 \bar{E}-01$

$0.4848 E-0 I$

0.6554 E- 01

0.8657 E- 01

O.1117E OO

$0.1409 E$ OO

0.1738 E 00

$0.2096 E 00$

$0.2472 E 00$

$0.2854 E 0$

$0.3227 E 00$

$0.3573 E 00$

0.3870 E 0

0.4132E 00

O.4320E Jo

0.4439E

0.4487E 00

$0.4467 E 00$

$0.4387 E 00$

0.4255 E 00

$0.3884 \angle \mathrm{CU}$

0.3668 E 00

$0.3445 E 00$

D. $3225 E$ OO

0.3013 E 00

$0.2813 E$ OO

$0.2628 E 00$

$0.2450 E$ OO

0.2307500

0.2170E 00

0

0.1937e 00

0.1837 E

0.

.1665e 00

0.1591 c 00

0.1523 C 60

0.1460 E 00

$0.1402 E 00$
$0.4132 E 00$

0.4083 E 00
C.1956E-06

$0.4750 E-05$

C.20 94E-04

$0.4743 E-06$

0.6658E- 5

O.

$0.2233 E-04$

$0.0956-04$

O.2012E-03

$0.5450 \mathrm{E}-02$

$\because 01350 E-02$

$0.6766 E-02$

$0.1359 \mathrm{E}-01$

$0.2541 E-01$

$0.4425 E-01$

0.71 89E- 01

$0.1090 E$ OO

$0.1546 E 00$

$0.2053 E 00$

0.2559E DO

$0.3003 E 00$

$0.3332 E$ OO

0. $3332 E 00$

O. 3530 0

C.3530E 0O

0.3416E OO

- $3206 E$ DO

$0.2944 E$ OO

$0.2669 E 00$

$0.2408 E 00$

$0.2177 E 00$

$0.1979 E$ OO

$0.1672 E$ OD

.1554E 00

$0.1453=0$

C.1287E

0.1

$0.1218 E$ D

O.1155E 00

$0.1099 E$ O.

0.1000 E 00

$0.9567 E-0$

$0.9166 \mathrm{E}-01$

$0.8793 E-01$

C. $8447 E-01$

$0.8123 E-01$

$0.7820 E-01$
$0.1843 E-05$

- IBILE 00
$0.0000 E 00$

0. $3218 E-71$

$0.5112 E-58$

$0.6516 E-52$

$0.3885 E-46$

0. $1084 E-40$

O.

. $1413 \mathrm{E}-35$

. $8622 E-31$

0. 2460 E-26

$0.3283 E-22$

$0.2049 \mathrm{E}-18$

$0.5981 E-15$

$0.8166 \mathrm{E}-12$

$0.5214 E-C 9$

0.1557E-05

$0.2176 E-04$

$0.4461 E-05$

$0.1529 E-03$

$0.2514 E-02$

0. $201 \mathrm{IE}-01$

0.8018 E-01

0.1674 - 1

0. O. 2029E 00 O. 734 E 00 $0.1344 E 00$ $0.1092 E 00$

$0.9349 E-01$

$0.8245 E-01$

$0.7404 \mathrm{E}-01$

$0.6733 E-01$

$0.6180 \mathrm{E}-01$

0.5715 E-C1

$0.5316 E-01$

0.4969 E-01

$0.4664 \mathrm{E}-0$ ?

C. $4394 \mathrm{E}-\mathrm{C}$

$0.4151 E-01$

C. $3933 E-01$ 0 3735 E-O $0.3755=01$ 0.350

-

$0.3238 \mathrm{E}-01$

O.

$0.2968 \mathrm{E}-01$

0.2847 E 01

$0.2735 E-01$

0.2630 E-01

$0.2531 E-01$

$0.2439 \mathrm{E}-01$

0. $2352 E-01$
41700.0

$\mathrm{C} / \mathrm{Cmp}$

$0.0000 E 00$

O.DODOE DO

$0.0000 E 00$

0.0000 00

0.0000 E

0.0000e 00

- co ode 00

0.000 00

0.000 O 00

.0.000 oo

0.00DOe no

$0.0000 E 00$

$0.4675 E-65$

$0.1698 E-53$

$0.4887 E-43$

0.111 EE -33

$0.2016 \mathrm{E}-25$

$0.2889 E-18$

0.3281 E-12

$0.2953 E-07$

0.4485 E-06

$0.3130 E=03$

$0.1924 E-01$

$0.1212 E 0$

0.133 SE OO

$0.8943 E-D 1$

0.691 BE-OI

$0.5785 E-01$

0.5020 E-0 1

$0.4454 \mathrm{E}-01$

$0.4013 E-01$

$0.3658 E-01$

$0.3362 E-01$

$0.3113 E-01$

$0.2898 E-51$

$0.2710 E-01$

$0.2545 E-01$

$0.2398 \mathrm{E}-01$

$0.2267 E-01$

$0.2148 E-01$

$0020415-01$

$0.2041=01$ $01943=-01$ $0.1853 E-01$

$0.1770 E-01$

-0.1693E-01

$-0.1624 E-04$

0.1557 E-01

$0.1495 E-01$

$0.1438 E-0$

$0.1384 E-01$

$0.1334 E-01$

$0.1287 \varepsilon-01$ 
FIG. 2: DIMENSIONLESS SOLUTION FOR QUANTIFYING TRACER BEHAVIOR IN A FIVE-SPOT PATTERN






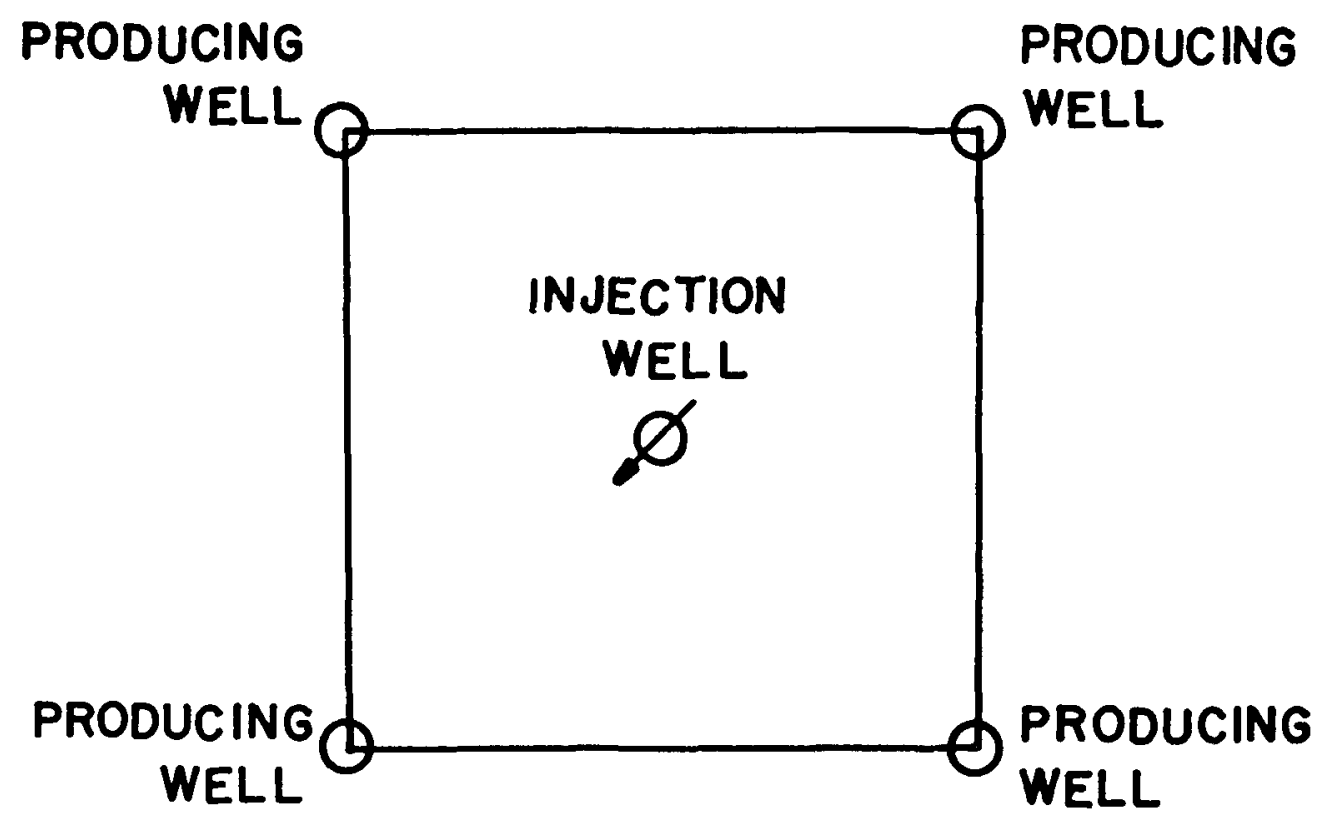

FIVE -SPOT PATTERN

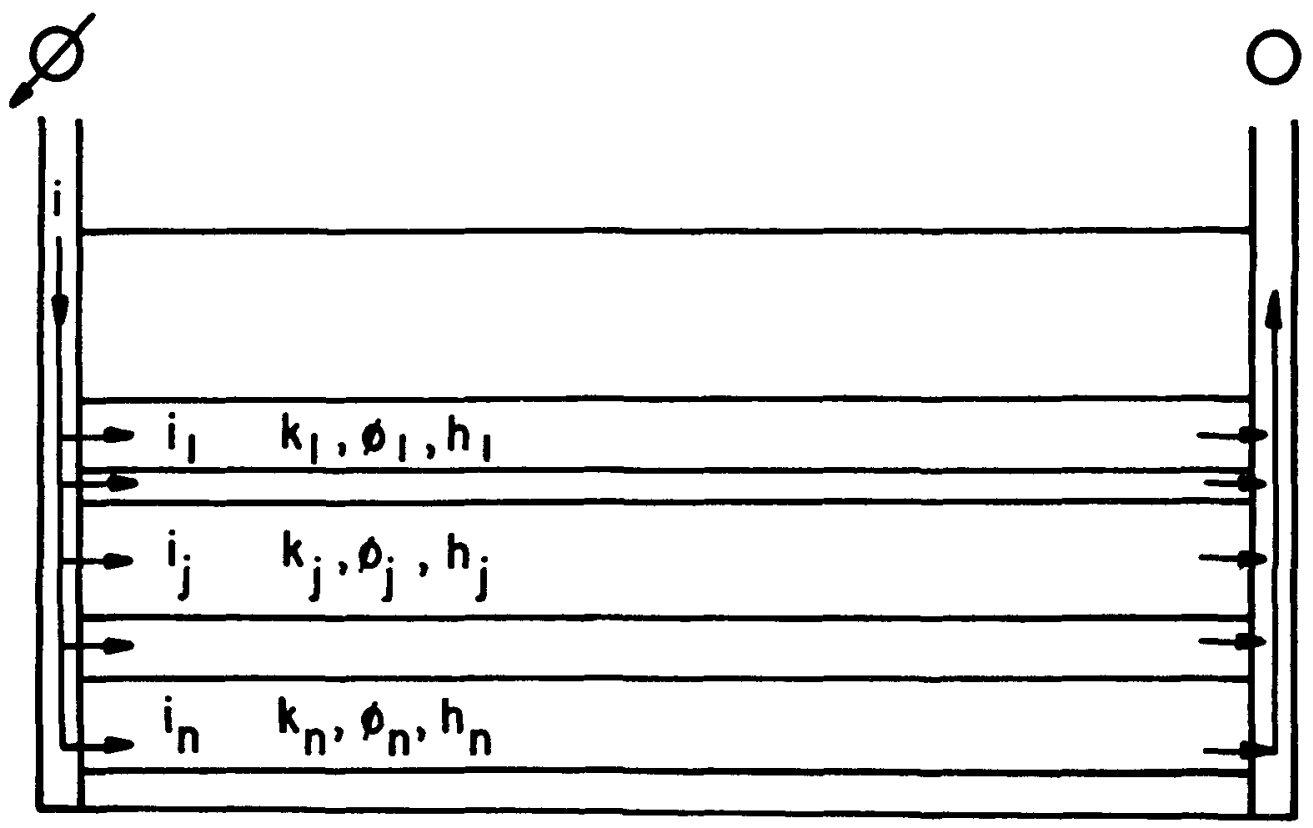

\section{n-LAYERED RESERVOIR}

FIG. 3: MULTI-LAYERED, FIVE-SPOT MODEL ASSUMED BY THE ALGORITHM 


$$
i_{j}=i \cdot \frac{(k h)}{j k h}
$$

where $i$ is the total injection rate.

The total fluid injected into layer $j, v_{j}$, is

$$
V_{j}=i_{j} \cdot \operatorname{TIME}=i \cdot \frac{(k h)}{\sum k h} \cdot \operatorname{TIME}=V \cdot \frac{(k h)}{\sum k h}
$$

where $\mathrm{V}$ is the total injection volume in barrels.

The pore volume injected into layer $j, \mathrm{PV}_{j}$, can be then described as

$$
P V_{j}=\frac{V_{j} \cdot 5.615}{A(h \phi)_{j} S_{w}}=\frac{5.615}{A(h \phi)_{j w} S_{w}} \quad V \frac{(k h)_{j}}{\sum k h}=\frac{5.615}{A S_{w}} \cdot \frac{k_{j}}{\phi_{j} \sum k h} \cdot V
$$

where $A$ = injection pattern area, sq $\mathrm{ft}$

$$
\begin{aligned}
(h \phi)_{j} & =\text { porosity-thickness of layer } j, f t \\
S_{w} & =\text { water saturation, fraction }
\end{aligned}
$$

We can assume that the arrival of a concentration peak in the field data corresponds with the arrival of a concentration peak from one of the layers. As will be discussed later, this is only an approximation of the actual arrival of a layer's peak, but it will still give reasonably accurate answers.

The location of the peak in the dimensionless solution $P V_{p}$, varies with $L / \alpha$. As shown in Fig. 4, the following empirical equation relates $\mathrm{PV}_{\mathrm{p}}$ and $\mathrm{L} / \alpha$

$$
\mathrm{PV}_{\mathrm{p}}=.72+.580541(\mathrm{~L} / \alpha)^{-.430043}
$$




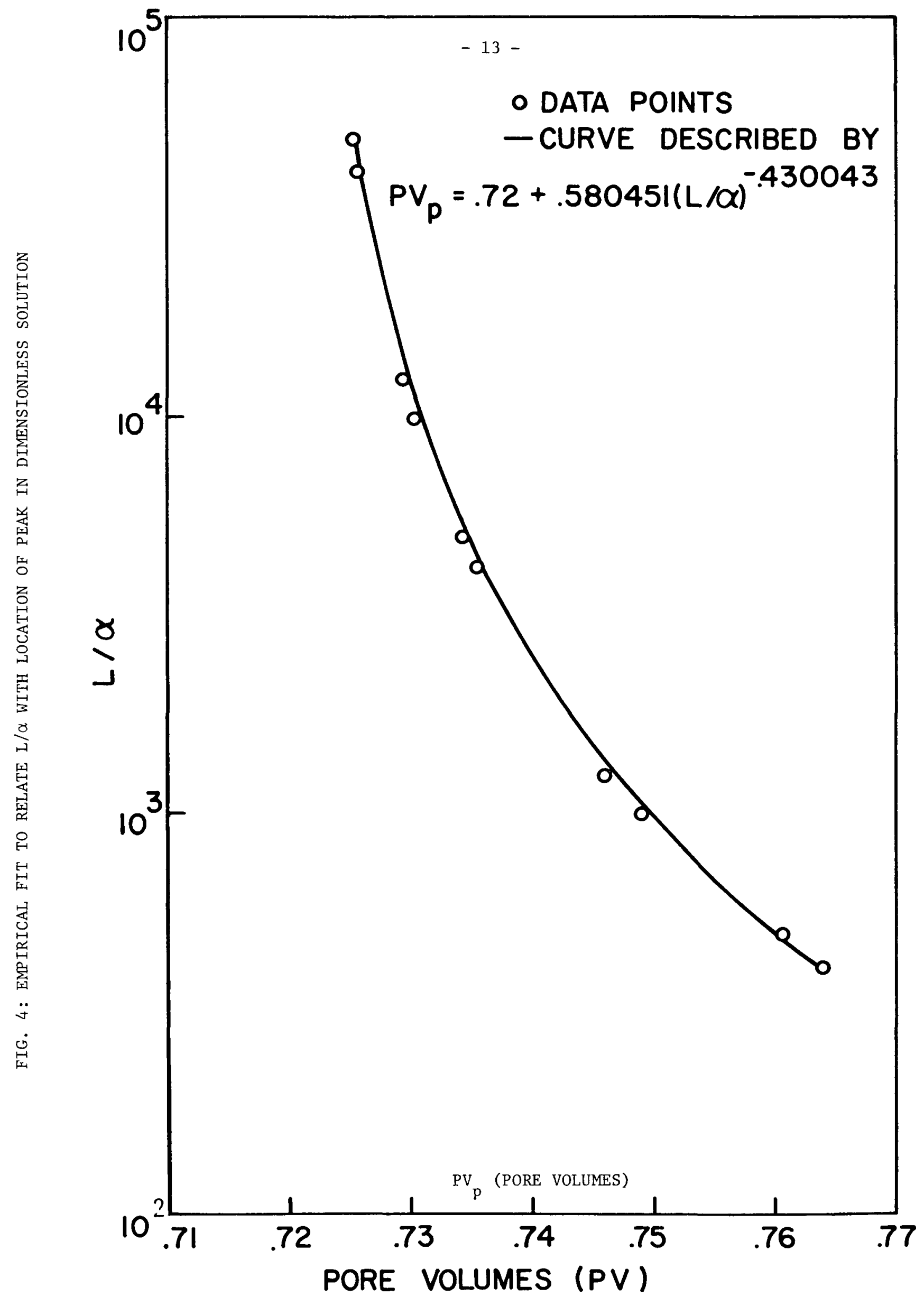


This equation was derived by fitting a least-squares log-log straight Iine through the $P V_{p}$ versus $L / \alpha$ data and by noting that $P V_{p}$ approaches .72 when $\mathrm{L} / \alpha$ approaches infinity. Knowing $\mathrm{L} / \alpha$, we can now calculate $\mathrm{PV}_{\mathrm{p}}$. If $\alpha$ is assumed to be the same for each layer, then this $\mathrm{PV}_{\mathrm{p}}$ is the same for each layer also.

Taking the total injection volume at which a peak occurs at the producing well and this calculated value for $\mathrm{PV}_{\mathrm{p}}$, we can then use $\mathrm{Eq}$. 11 and solve for

$$
\frac{\mathrm{k}_{j}}{\phi_{j} \Sigma \mathrm{kh}}=\frac{\mathrm{PV}_{\mathrm{p}}}{\mathrm{V}_{\mathrm{pj}}} \frac{\mathrm{AS}_{\mathrm{w}}}{5.615}
$$

If there are $\mathrm{n}$ peaks, we can infer $\mathrm{n}$ layers and calculate a separate value that is characteristic of each layer. Once we know this value of $\mathrm{k} / \phi \sum \mathrm{kh}$ for a layer, then we can use $\mathrm{Eq} .11$ to calculate $\mathrm{PV}_{j}$ for any $\mathrm{V}$ we desire. Knowing $\mathrm{PV}_{j}$, we can calculate a value for $\mathrm{C} / \mathrm{Cmp}$ for that layer at that $\mathrm{V}$. Equation 15 in Brigham and Smith's paper relates the Cmp for a layer to the weight of tracer entering the layer.

$$
\mathrm{m}=400 \mathrm{~h} \phi \mathrm{S}_{\mathrm{w}} \mathrm{Cmp} \mathrm{L}^{1.5} \alpha^{.5}
$$

where Cmp is in units of weight fraction and $m$ is the weight of tracer in pounds.

Rearranging this equation and converting Cmp to units of parts per million, we get for layer $j$ :

$$
\operatorname{Cmp}_{j}=\frac{m_{j}}{.0004(h \phi)_{j} S_{w} L^{1.5} \alpha^{.5}}
$$


For any value of $\mathrm{C}_{j} / \mathrm{Cmp}_{j}$ that we obtain from the dimensionless solution, we can calculate the tracer concentration in the fluid entering the producing well from layer $\mathbf{j}$ as:

$$
C_{j}=\frac{C_{j}}{C m p_{j}} \cdot C_{m}=\frac{C_{j}}{C m p_{j}} \cdot \frac{m_{j}}{.0004(h \phi)_{j} S_{w} L^{1.5} \alpha .5}
$$

If the amount of tracer in layer $j, \dot{m}_{j}$, is assumed to be proportional to $\mathrm{kh}$, then:

$$
\mathrm{m}_{\mathrm{j}}=\mathrm{m} \cdot \frac{(\mathrm{kh}) \mathrm{j}}{\sum \mathrm{kh}}
$$

where $\mathrm{m}$ is the total amount of tracer injected into the reservoir in pounds.

$\mathrm{C}_{j}$ can then be expressed as:

$$
\begin{aligned}
C_{j} & =\frac{C_{j}}{C m p_{j}} \cdot \frac{m}{.0004(h \phi){ }_{j} S_{w} L^{1.5} \alpha^{.5}} \cdot \frac{(k h)_{j}}{\sum k h} \\
& =\frac{C_{j}}{C m p_{j}} \cdot \frac{m}{.0004 s_{w} L^{1.5} \alpha^{.5}} \cdot \frac{k_{j}}{\phi_{j}^{\Sigma k h}}
\end{aligned}
$$

Upon entering the wellbore, this fluid from layer $\mathbf{j}$ is mixed with fluids from the other layers. This mixing gives us the overall concentrations seen in the wellbore. If the amount of fluid entering the producing wellbore from each layer is proportional to the kh of each layer, then the overall concentration can be expressed as a weighted sum: 


$$
\begin{aligned}
C & =\Sigma C_{j} \cdot \frac{(k h)_{j}}{\sum k h} \\
& =\Sigma \frac{C_{j}}{C m p_{j}} \cdot \frac{m}{.0004 S_{w} L^{1.5} \cdot 5} \cdot \frac{k_{j}}{\phi_{j} \sum k h} \cdot \frac{(k h)_{j}}{\sum k h}
\end{aligned}
$$

Since $\mathrm{k}_{j} / \phi_{j} \sum \mathrm{kh}$ was calculated in $\mathrm{Eq} \cdot 13$, and $\mathrm{C}_{j} / \mathrm{Cmp} \mathrm{j}_{\mathrm{j}}$ can be calculated from the dimensionless solution, the unknowns of this equation are the terms $(\mathrm{kh})_{j} / \Sigma \mathrm{kh}$. If we take $\mathrm{n}$ values of $\mathrm{C}$ from our field data, we can write $n$ equations in the form of Eq. 19. For an $n$ layer system, this means we will have a system of $n$ equations and $n$ unknowns. In our algorithm, we will use the concentration values at the $n$ peaks found in the field data. However, any $n$ points could have been used. Letting $\mathrm{CP}_{i}$ (for $i=1, \ldots, n$ ) be the data points we pick out from our field, we can rewrite Eq. 19 as:

$$
\begin{aligned}
C p_{i} & =\sum\left(\frac{C_{j}}{C m p_{j}}\right)_{i} \frac{m}{.0004 s_{w} L^{1.5} \alpha^{\cdot 5}} \frac{k_{j}}{\phi_{j} \Sigma k h} \cdot \frac{(k h)}{\sum k h} \\
\text { Setting } a(i, j) & =\left(\frac{C_{j}}{C m p_{j}}\right)_{i} \frac{m}{.0004 s_{w} L^{1.5} \cdot 5} \frac{k_{j}}{\phi_{j}^{\Sigma k h}} \\
x(j) & =(k h)_{j} / \Sigma k h \\
b(i) & =C p_{i}
\end{aligned}
$$

We now have an $n \times n$ matrix equation of the form $\vec{b}=\overrightarrow{A x}$.

After solving this matrix equation, we have a value for $(\mathrm{kh})_{j} / \mathrm{kh}$ as we11 as $\mathrm{kj} / \phi ; \sum \mathrm{kh}$ to characterize each layer. We can divide one by the other to get $(\phi k)_{j}$. 


$$
(\phi h)_{j}=\frac{(k h)_{j}}{\sum k h} \div \frac{k_{j}}{\phi_{j} \sum k h}
$$

The ratio $\mathrm{kh} / \Sigma \mathrm{kh}$ can be thought of as a term describing the layer's relative conductance, and $\phi \mathrm{h}$ can be thought of as describing the layer's capacity.

Attached as Appendix $B$ is a computer program to carry out this algorithm. Given the necessary input data, it will calculate values for $\mathrm{kh} / \mathrm{kh}$ and $\mathrm{h} \phi$ for each layer. It will then take these values and generate expected values for overall concentration versus total volume injected. These values can be compared with the field data to judge the accuracy of the analysis.

The necessary input data are:

(1) $\mathrm{L}=$ distance between injector and producer, ft,

(2) alpha $=$ dispersion constant defined in the Brigham and Smith paper, ft,

(3) $n=$ number of layeirs expected,

(4) $\mathrm{m}=$ total weight of tracer injected, 1bs,

(5) $\mathrm{S}_{\mathrm{w}}$ = water saturation in the reservoir, fraction,

(6) area $=$ area of injection pattern, sq ft,

(7) $V_{\min }, V_{\max }=$ this sets the range at which the "overall concentration" versus "total injection volume" values will be calculated for comparison with the field data. The program will generate 51 values between $V_{\min }$ and $V_{\max }$, inclusive,

(8) $V p(j)=$ location of each peak in the field data in units of bbls,

(9) $\mathrm{Cp}(j)=$ height of each peak in the field data in concentration units of parts per million.

The following flowchart summarizes the steps taken by this program. 
FLOWCHART FOR COMPUTER ALGORITHM
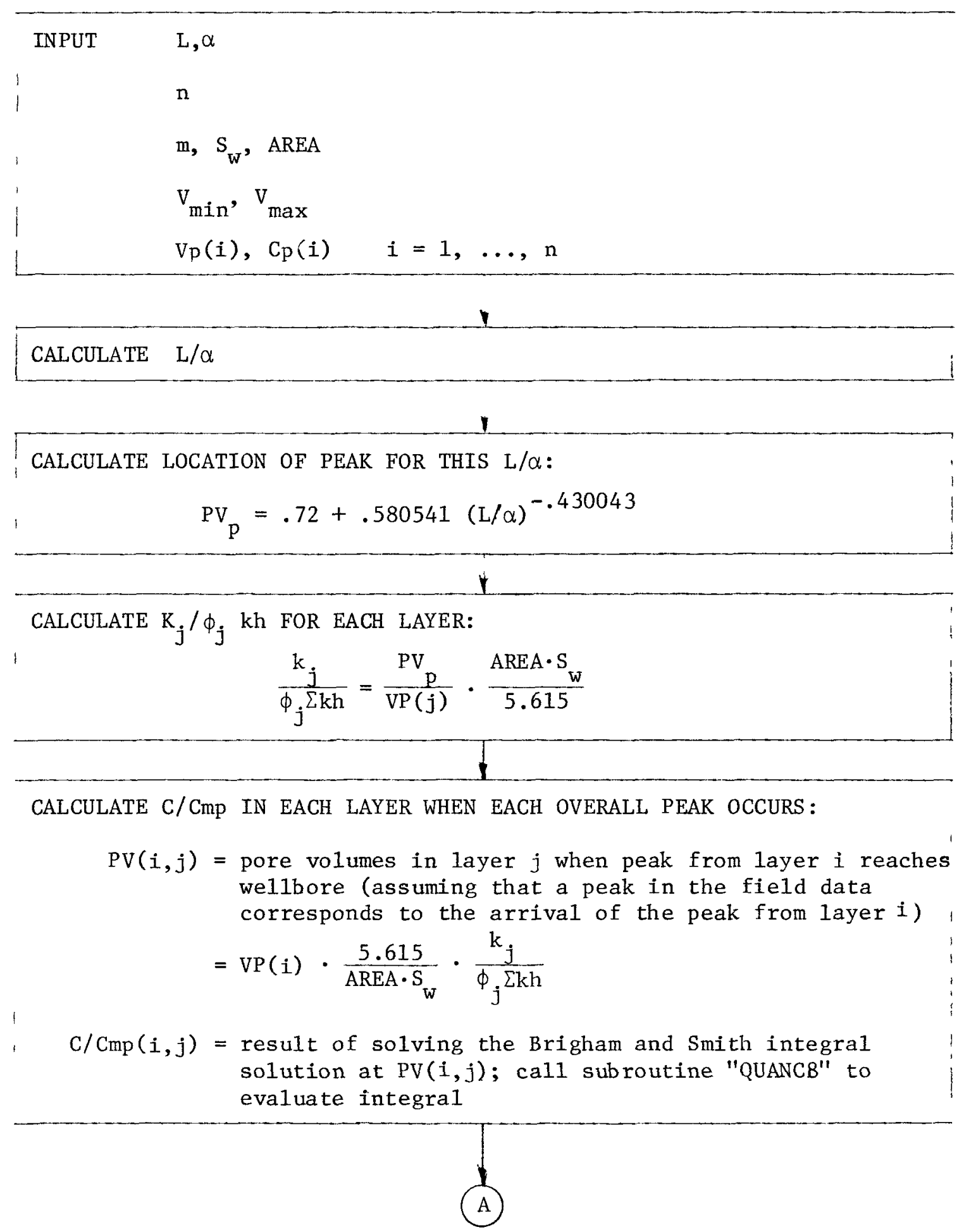


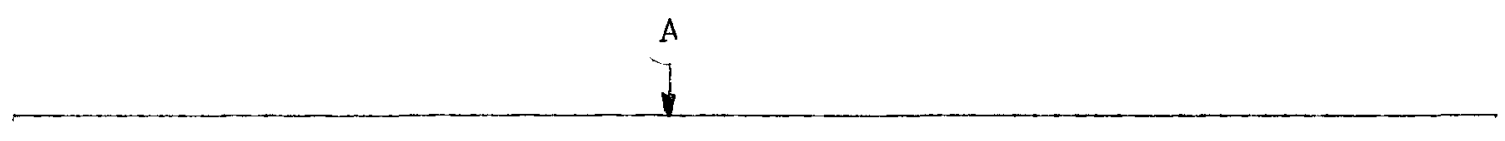

CALCULATE EACH ELEMENT OF THE MATRIX:

$$
a(i, j)=\frac{C}{C m p}(i, j) \cdot \frac{m}{.0004 \cdot S_{w} \cdot L^{1.5} \cdot \alpha^{.5}} \cdot \frac{k_{j}}{\phi_{j} \Sigma k h}
$$

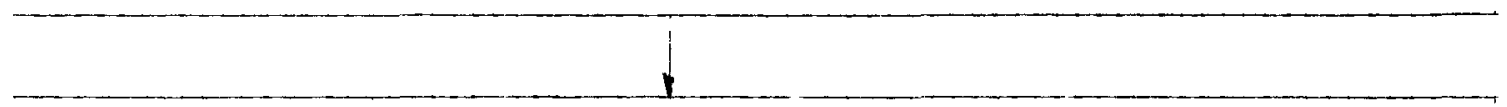

USE THE HEIGHT OF EACH FIELD DATA PEAK [CP(i)] AS THE ELEMENTS OF VECTOR $\vec{b}$; USE $\mathrm{kh} / 2 \mathrm{kh}$ AS THE ELEMENTS OF THE UNKNOWN VECTOR $\vec{x}$; THEN SOLVE THE MATRIX ${ }^{\mathrm{j}}$ EQUATION $\overrightarrow{\mathrm{b}}=\mathrm{Ax}$ USING SUBROUTINES "DECMP1" AND

"SOLVE1": THIS WILL GET VALUES FOR $\mathrm{kh}_{\mathrm{j}} / \Sigma \mathrm{kh}$.

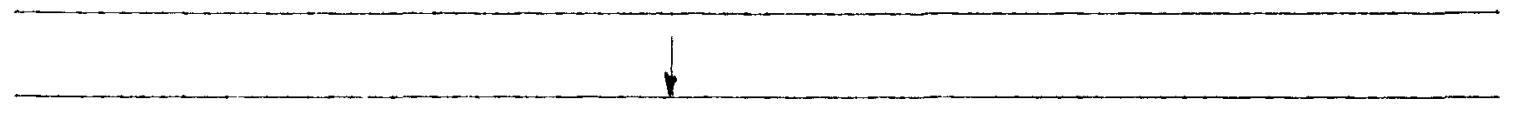

CALCULATE $h \phi$ FOR EACH LAYER: 1

$$
(h \phi)_{j}=\frac{(k h)_{j}}{\sum k h} \div \frac{k_{j}}{\phi_{j} \Sigma k h}
$$

TO GENERATE CONCENTRATION VS INJECTION VOLUME DATA:

CALCULATE V AT WHICH CONCENTRATION VALUES ARE DESIRED, STARTING WITH , $\mathrm{V}_{\min }$ AND ENDING WITH $\mathrm{V}_{\max }$ (C)

CONVERT V TO PV FOR EACH LAYER BY:

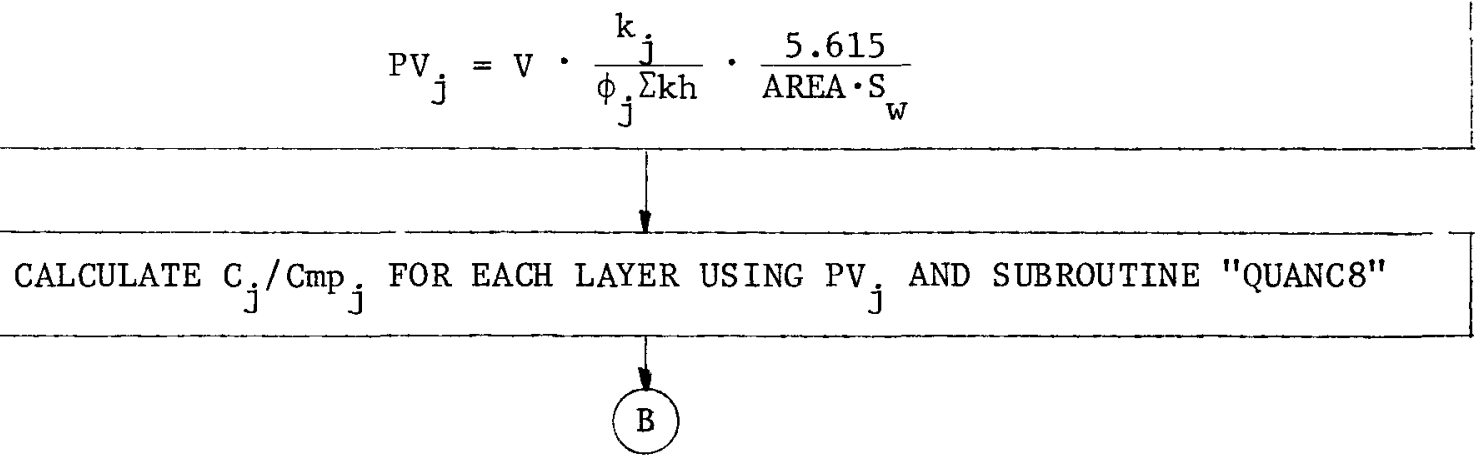


(B)

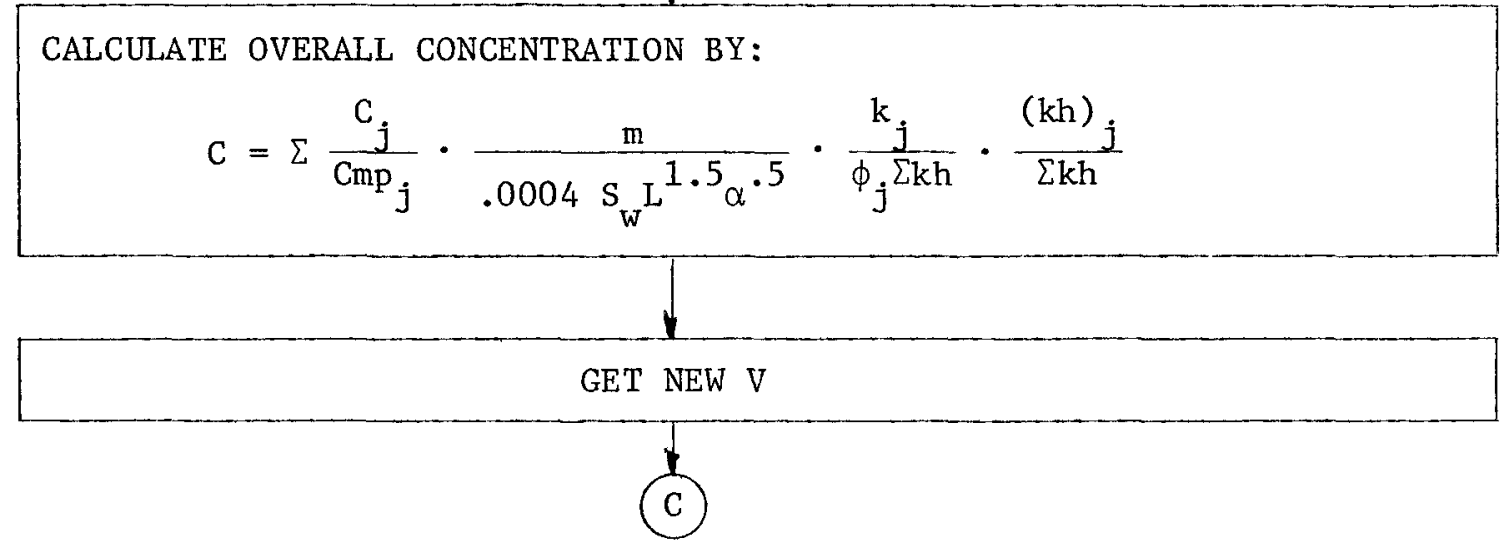




\section{APPLICATION AND DISCUSSION OF RESULTS}

Figures 5, 6, and 7 show the results of applying this computer program to three different sets of simulated field data for a two-layer reservoir. The solid line on each figure represents the simulated data and the triangular points show the match obtained by the program. The input values for $\mathrm{kh} / \mathrm{kh}$ and $\mathrm{h} \phi$ used to generate the simulated data are shown on Table III. For comparison, Table III also shows the corresponding values of $\mathrm{kh} / \Sigma \mathrm{kh}$ and $\mathrm{h} \phi$ calculated by the program.

As these results show, the program was able to accurately calculate $\mathrm{kh} / \mathrm{kh}$ and $\mathrm{h} \phi$ values for each layer. The farther apart the peaks in the data were, the more accurate the analysis. But even in the worst case of Example 3, where one peak is almost hidden by the other, the error in $\mathrm{kh} / \sum \mathrm{kh}$ and $\mathrm{h} \phi$ is under five percent.

This error that results when the peaks are close together can be attributed to the assumption made in the algorithm that a peak in the field data corresponds with the arrival to the wellbore of a peak from one of the layers.

When the peaks are far apart, the shape of the overall concentration curve is dominated by the tracer in only one layer at a time. In this case, the peak in the overall curve corresponds extremely closely with the arrival of a peak in one of the layers. However, in the case where the peaks are close together, the shape of the overall curve can be affected by more than one 1ayer. 
TABLE III: RESULTS OF ANALYZING SIMULATED FIVE-SPOT TRACER TEST DATA

\begin{tabular}{|c|c|c|c|c|c|c|c|c|}
\hline \multirow[b]{2}{*}{ EXAMPLE } & \multirow[b]{2}{*}{ LAYER } & \multicolumn{5}{|c|}{$\begin{array}{l}\text { PARAMETERS USED TO } \\
\text { GENERATE SIMULATED DATA }\end{array}$} & \multicolumn{2}{|c|}{$\begin{array}{l}\text { RESULT OF } \\
\text { ANALYSIS }\end{array}$} \\
\hline & & $\mathrm{K}(\mathrm{md})$ & $h(f t)$ & $\phi$ & $\mathrm{kh} / \Sigma \mathrm{kh}$ & $\mathrm{h} \phi$ & $\mathrm{kh} / \Sigma \mathrm{kh}$ & $\mathrm{h} \phi$ \\
\hline \multirow[t]{2}{*}{1} & 1 & 1,000 & 1 & .30 & .182 & 0.30 & .1811 & 0.298 \\
\hline & 2 & 500 & 9 & .20 & .818 & 1.80 & .8182 & 1.800 \\
\hline \multirow[t]{2}{*}{2} & 1 & 1,000 & 3 & .30 & .462 & 0.90 & .4618 & 0.900 \\
\hline & 2 & 500 & 7 & .18 & .538 & 1.26 & .5373 & 1.256 \\
\hline \multirow[t]{2}{*}{3} & 1 & 750 & 4 & .25 & .500 & 1.00 & .4733 & 0.952 \\
\hline & 2 & 500 & 6 & .18 & .500 & 1.08 & .4908 & 1.055 \\
\hline \multirow[t]{5}{*}{4} & 1 & 1,000 & 1 & .35 & .233 & 0.35 & .2327 & 0.350 \\
\hline & 2 & 750 & 1 & .30 & .174 & 0.30 & .1732 & 0.297 \\
\hline & 3 & 400 & 2 & .18 & .186 & 0.36 & .1860 & 0.358 \\
\hline & 4 & 500 & 1 & .25 & .116 & 0.25 & .1180 & 0.252 \\
\hline & 5 & 250 & 5 & .14 & .291 & 0.70 & .2925 & 0.703 \\
\hline \multirow[t]{3}{*}{5} & 1 & 1,000 & 1 & .40 & .286 & 0.40 & .2861 & 0.401 \\
\hline & 2 & 500 & 1 & .28 & .143 & 0.28 & .1369 & 0.267 \\
\hline & 3 & 250 & 8 & .15 & .571 & 1.20 & .5765 & 1.209 \\
\hline
\end{tabular}

In all above cases:

Total mass of tracer injected, $\mathrm{m}=200 \mathrm{lbs}$

Distance between injector and producer, $\mathrm{L}=233.3 \mathrm{ft}$

Area of pattern, $A=108,858 \mathrm{ft}^{2}$

Dispersion constant, $\alpha=0.05 \mathrm{ft}$

Water saturation, $\mathrm{S}_{\mathrm{w}}=0.55$ 


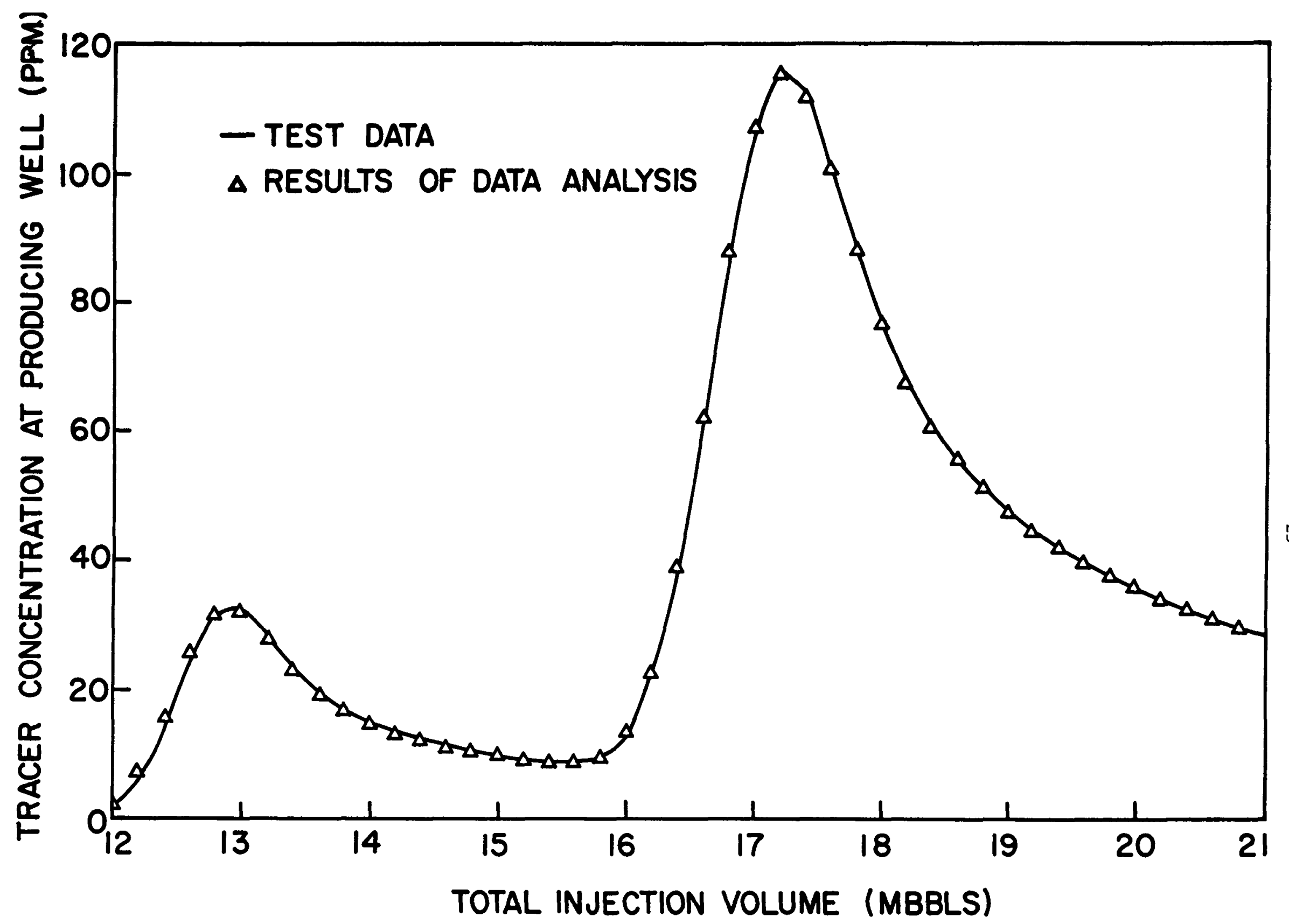

FIG. 5: RESULTS OF ANALYZING DATA OF EXAMPLE 1 


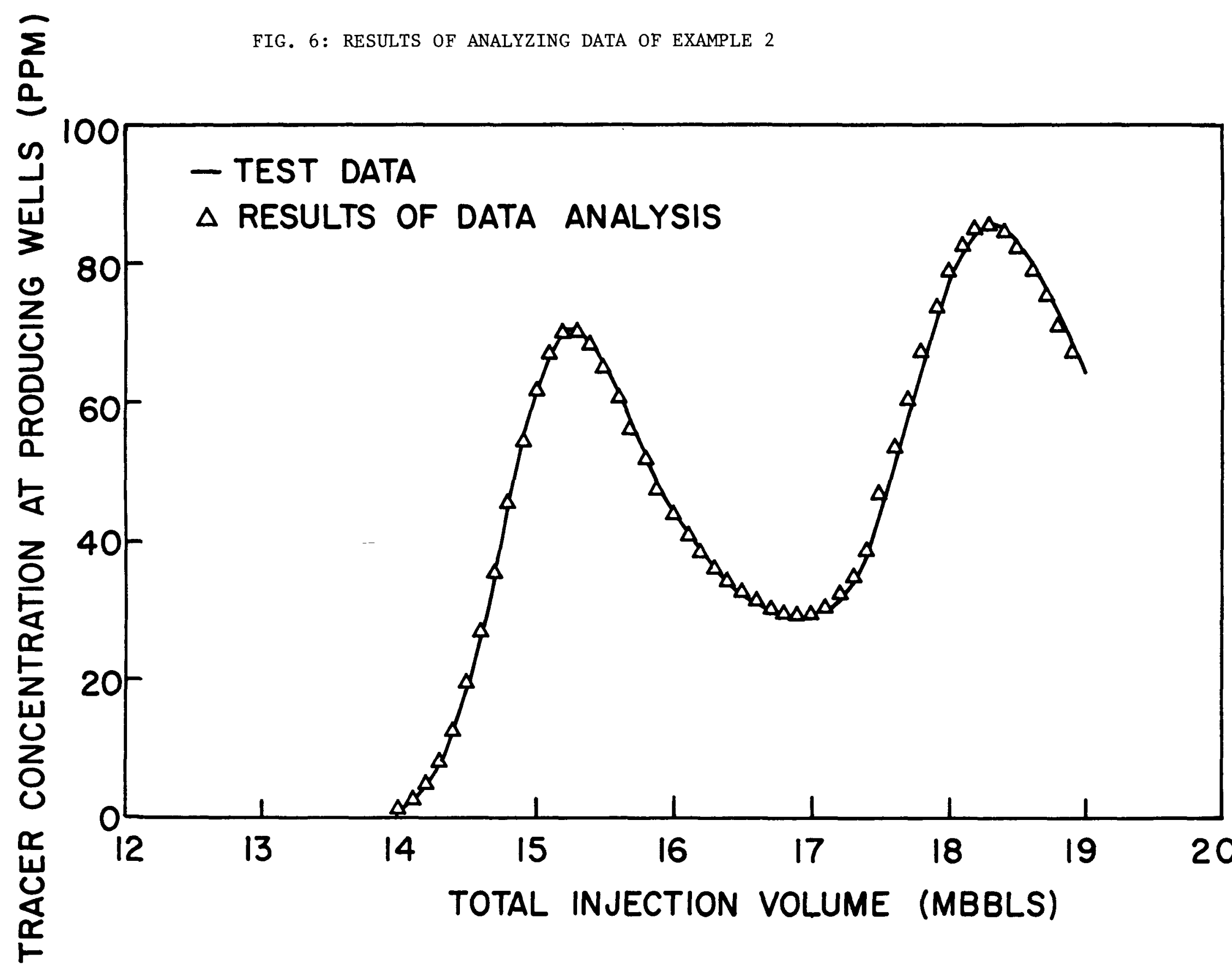




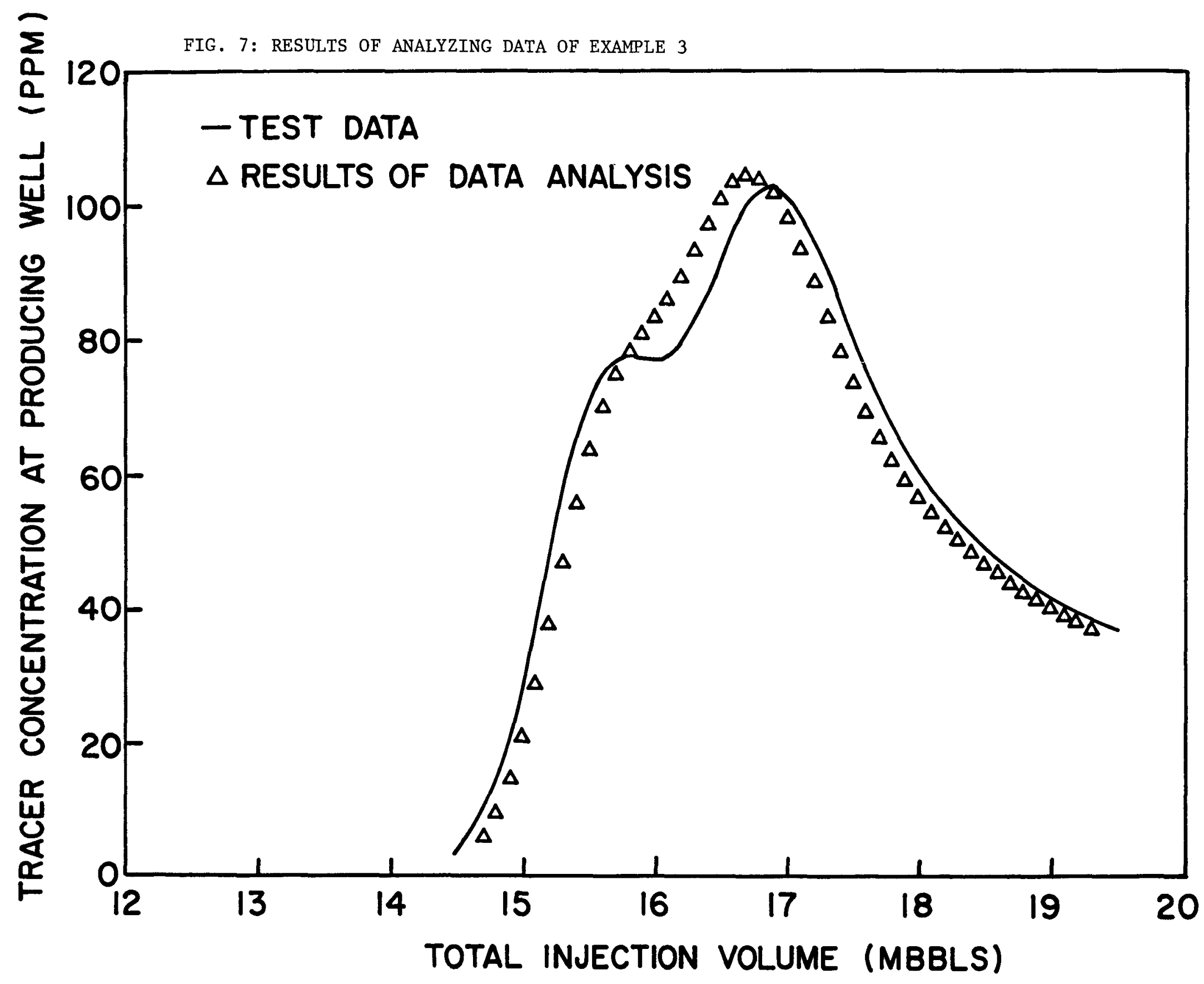


A more analytical way of looking at this effect is to note that when two equally weighted peaking curves are added together, the peaks in the resulting curve appear at the locations where the slopes of the individual curves are equal in magnitude but opposite in sign. If the peaks are close together, the locations of these equal but opposite slopes will be away from the location of the individual peaks. This same general idea controls the location of the peaks in the case of adding the unequally weighted curves of a tracer test.

To illustrate this point, the simulated overall concentration field data of Example 3 have been redrawn as the solid curve in the middle in Fig. 8. The concentration profiles for each of the two layers have been included at the bottom of the same figure. Note that the peaks of the individual curves are at 15,650 and 16,950 barrels, but that the peaks in the overall curve are at 15,775 and 16,850 barrels. The peaks in the individual concentration profiles appear to have "shifted" in location after being combined to get the overall curve.

When the data in Example 3 were analyzed using 15,775 and 16,850 barrels as the location of the peaks in the individual layers instead of 15,650 and 16,950 barrels, a noticeable error resulted in the calculation of $\mathrm{kh} / \mathrm{kh}$ and $\mathrm{h} \phi$. The error is also demonstrated by the difference between the field data curves and the curves outlined by the triangular points in Fig. 8. These outlined curves are the concentration profiles calculated by the algorithm for the individual layers and for the overall system.

To get a more accurate calculation of $\mathrm{kh} / \Sigma \mathrm{kh}$ and $\mathrm{h} \phi$, we could:

(1) look at Fig. 7 and see that the true location of the peaks in the individual layers must be farther apart than we had assumed before, 
FIG. 8: CONCENTRATION PROFILES FOR EXAMPLE 3

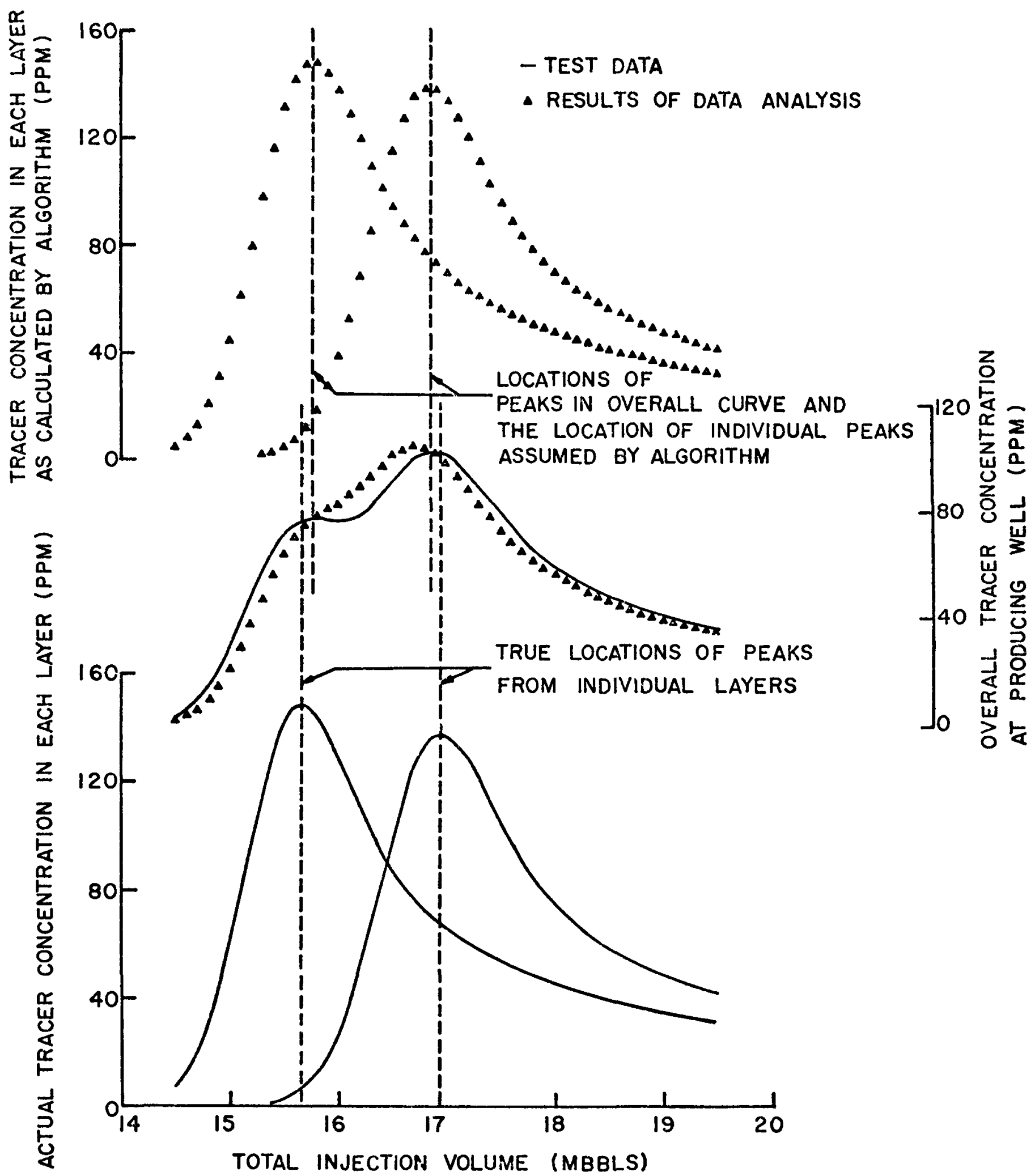


(2) guess a true location for each of the peaks. The guesses could be guided by trying to determine where the slopes of the individual curves would be equal in magnitude and opposite in sign,

(3) rerun the program using the new guesses,

(4) compare the new calculated overall concentration values with the field data.

We could continue this process until we got an acceptable match with the field data.

Further work can be done on this problem by finding an analytical method or a computerized iterative method to locate the true individual peak locations.

To demonstrate the use of this program with a system of more than two peaks, Example 4 on Table III shows the results of a hypothetical five-layer problem. The program included as Appendix $B$ in this paper is written to handle up to a five-layer system. It can be modified to handle any multi-layer system by simply changing the dimension of the array and the vector variables.

The results for Example 4 are plotted on Fig. 9. The program gives fairly accurate calculations for $\mathrm{kh} / \Sigma \mathrm{kh}$ and $\mathrm{h} \phi$ for each layer, but, like Example 3, the close bunching of the peaks causes some error in the results .

One potential problem in analyzing field data is in determining the number of layers in the system. In cases where two peaks are very close together, one peak may be "hidden" in the data. Such a case is shown as Example 5 in Fig. 10. At first glance, there appears to be only two layers indicated by the two field data peaks. Upon applying the algorithm 


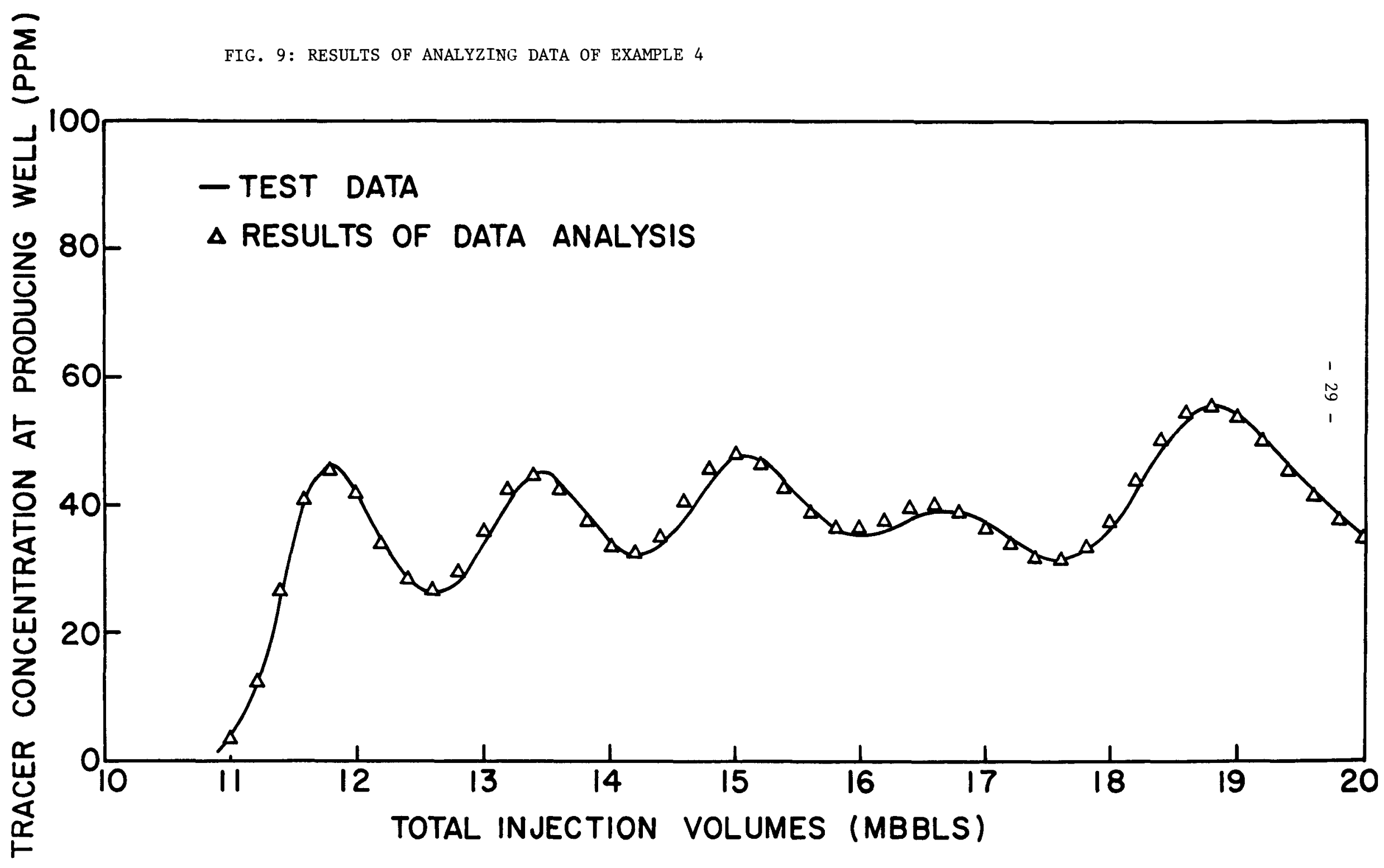







using these two peaks and assuming two layers, the triangular points of the figure show the resulting match. The large gap in the match around 15,000 barrels suggests the existence of another peak, and hence another 1ayer. As a first guess, we could assume that the third peak is located near the point where the separation of the match is the greatest. Rerunning the program assuming a third peak at 15,300 barrels resulted in the circular match points shown in Fig. 10. The process could be repeated by adjusting the guesses of a11 three peak locations until an acceptable match is obtained.

As a last example, Fig. 11 shows the results of applying the algorithm to an actual tracer test. The field data used here have been pre. sented in Brigham and Smith's paper as the ammonium thiocyanate tracer test in Well D. It is redrawn as the solid curve on Fig. 11.

From the solid curve, peaks were picked at 2,650 barrels at $30 \mathrm{ppm}$ 2,980 barrels at $28.5 \mathrm{ppm}, 3,240$ barrels at $31.5 \mathrm{ppm}$, and 3,620 barrels at $27.5 \mathrm{ppm}$. As described in the Brigham and Smith paper, before the field data could be analyzed it had to be adjusted to account for the production of fluid from outside the injection pattern. The well produced an average of $240 \mathrm{BWPD}$, and it was estimated that the injector contributed 205 BWPD into the quadrant of the pattern drained by this producer. The other 35 BWPD must have been coming from outside the pattern. This outside water diluted the tracer entering the wellbore by a factor of $205 / 240$. The concentrations given in the field data therefore had to be multiplied by a factor of $240 / 205$ in order to make the concentrations compatible with the model assumed by the algorithm. The field data gave the location of the peaks as a function of fluid produced by the well instead of as a function of fluid injected into the 


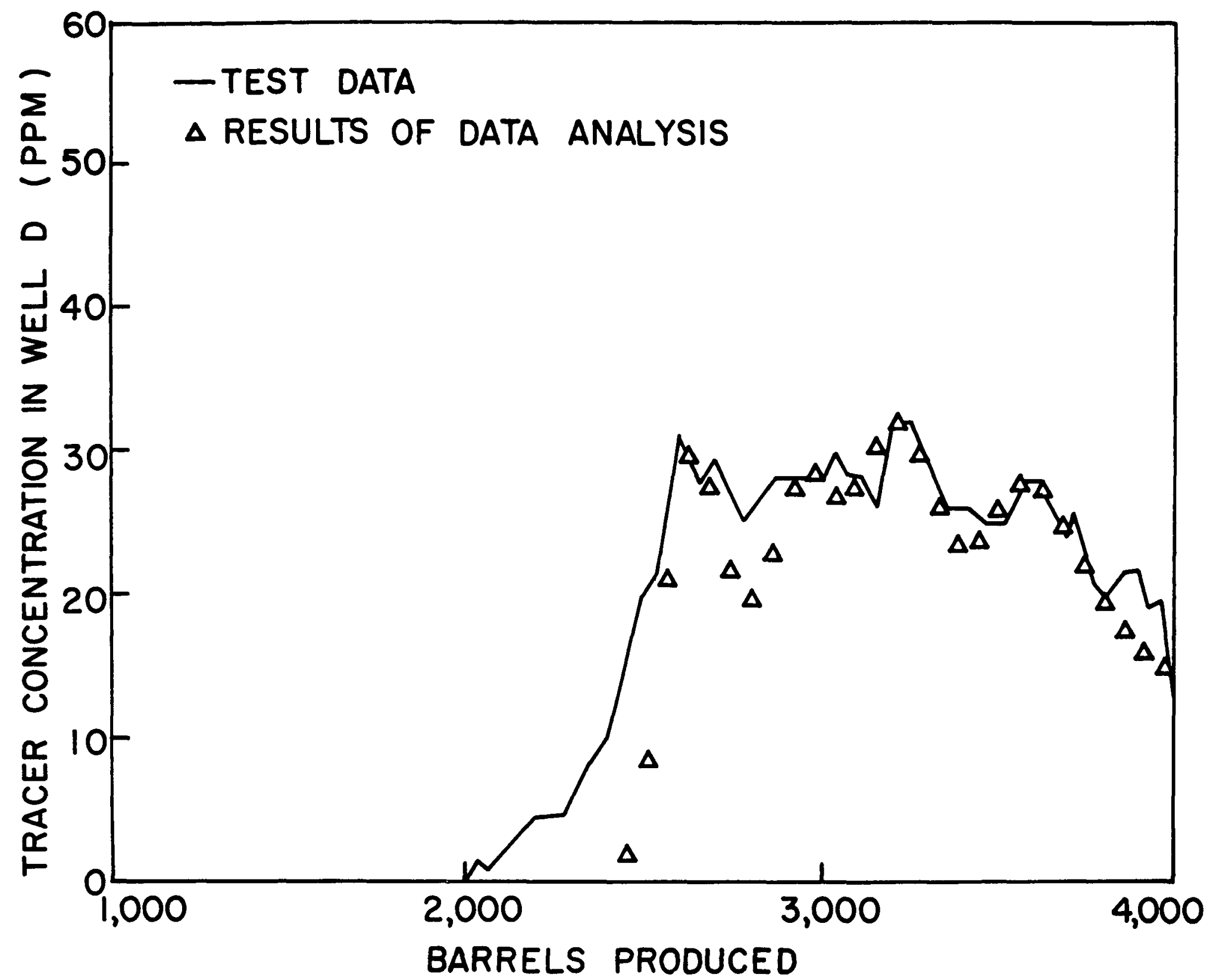

FIG. 11: ACTUAL FIELD DATA (AMMONIUM THIOCYANATE TRACER DATA FROM WELL D IN BRIGHAM AND SMITH'S PAPER [Ref. 1]) 
pattern. The "volumes injected" were determined by multiplying the "volumes produced" by 205/240. After adjustment, the peak locations and heights were input as 2,264 barrels at $35.1 \mathrm{ppm}, 2,545$ barrels at $33.4 \mathrm{ppm}, 2,768$ barrels at $36.9 \mathrm{ppm}$, and 3,092 barrels at $32.2 \mathrm{ppm}$. Since we are considering only Well $\mathrm{D}$, the pattern area input was one-fourth of two and one-half acres, or $27,225 \mathrm{sq} f t$. Also, since the injected fluid was not distributed equally among the producers, the value input for $\mathrm{m}$, the amount of tracer material, had to be adjusted to an "effective" value. If the injection fluid were equally distributed and We11 D received exact1y one-fourth of the 600 BWPD injected, or 150 BWPD, then the "effective" value for m for We11 D's system would be $2001 \mathrm{bs}$. However, since Well D received 205 BWPD of the injected fluid instead of 150 BWPD, it received a larger share of the tracer material. Its "effective" m was greater than 200 1bs by a factor of $205 / 150$. The value of $m$ used for this analysis was thus set at 273 lbs. The value of $\alpha$ used was 0.05 and the water saturation was 0.55 .

The results of this analysis are shown on Fig. 11 and Table IV. Four permeability streaks are assumed to be causing the concentration profile seen in the field data. As shown on the table, these four streaks are calculated to have $\mathrm{kh} / \Sigma \mathrm{kh}$ values of $0.1002,0.0664,0.0697$, and 0.0587 , and $h \phi$ values of $0.1157,0.0862,0.0983$, and 0.0925 . Since the four $\mathrm{kh} / \Sigma \mathrm{kh}$ values total 0.295 , this indicates that these four streaks make up only $29.5 \%$ of the total $\mathrm{kh}$ of the reservoir.

In their paper, Brigham and Smith report that the reservoir has a thickness of twelve feet, an average permeability of $1,500 \mathrm{md}$, and an average porosity of 0.26 . If we assume that this average porosity value applies to each layer, we can use these reservoir parameters and the 
TABLE IV: RESULTS OF ANALYZING ACTUAL FIELD DATA (WELL D AMMONIUM THIOCYANATE TRACER TEST DESCRIBED IN THE BRIGHAM AND SMITH PAPER [REF. 1])

LAYER

$$
1
$$$$
2
$$$$
3
$$$$
4
$$

$\mathrm{kh} / \Sigma \mathrm{kh}$

.1002

.0664

.0697

.0587 $\mathrm{h \phi}$

.1157 .0862

.0983 .0925

Assuming: average permeability $=1,500 \mathrm{md}$ total thickness $=12 \mathrm{ft}$ average porosity $=.26$ (assumed same for all layers)

Then: $\quad \sum \mathrm{kh}=1,500 \mathrm{md} \cdot 12 \mathrm{ft}=18,000 \mathrm{md}-\mathrm{ft}$

$$
\begin{aligned}
& \mathrm{kh}_{i}=\frac{\mathrm{kh}_{\mathrm{i}}}{\sum \mathrm{kh}} \cdot \sum \mathrm{kh}=\frac{\mathrm{kh}_{i}}{\sum \mathrm{kh}} \cdot 18,000 \mathrm{md}-\mathrm{ft} \\
& \mathrm{h}_{i}=\frac{(\mathrm{h \phi})_{i}}{\phi_{i}}=\frac{\mathrm{h} \phi}{.26} \\
& \mathrm{k}_{i}=\frac{(\mathrm{kh})_{i}}{\mathrm{~h}_{i}}
\end{aligned}
$$

\section{LAYER}

1
2
3
4 $\underline{k h(m d-f t)}$

1,804

1,195

1,255

1,057 $\underline{h(f t)}$

$$
.445
$$$$
.332
$$

.378

$\frac{.356}{1.511}$ $\underline{k(m d)}$

4,050

3,600

3,320

2,970 
$-35-$

$\mathrm{kh} / \Sigma \mathrm{kh}$ and $\mathrm{h} \phi$ numbers to obtain the permeability and thickness of each streak. We find that these four streaks have permeabilities ranging from $2,970 \mathrm{md}$ to $4,050 \mathrm{md}$ and that they total about one and one-half feet in thickness. This compares reasonably well with the analysis performed by Brigham and Smith that found three streaks totaling about two and one-half feet thick and ranging from $2,980 \mathrm{md}$ to $4,110 \mathrm{md}$. 
IV. CONCLUSIONS

As a result of this work, the following conclusions were reached:

(1) The location of the peaks in Brigham and Smith's dimensionless solution for tracer flow in a five-spot injection pattern can be empirically related to $L / \alpha$ by:

$$
\mathrm{PV}_{\mathrm{p}}=.72+.580541(\mathrm{~L} / \alpha)^{-.430043}
$$

(2) The algorithm presented in this paper can calculate $\mathrm{kh} / \mathrm{kh}$ and $h \phi$ values for a multi-layered reservoir from the type of data obtained from five-spot tracer tests.

(3) The farther apart the peaks in the field data, the more accurate the analysis.

(4) Cases where the peaks are close together result in noticeable errors because the location of a peak in the field data does not quite correspond to the arrival of a peak in one of the layers. However, of the cases examined here, the errors calculated for $\mathrm{kh} / \Sigma \mathrm{kh}$ and $\mathrm{h} \phi$ were less than five percent in the worst case. Rerunning the program several times with adjusted peak locations will probably allow one to locate the correct values.

(5) The method can be applied to locate additional peaks (and therefore additional layers) that can be obscured by the overall concentration data. 


$$
-37-
$$

(6) The algorithm can be applied to actual field data if the data are first put in a form that is compatible with the model assumed by the algorithm. 


\section{NOMENCLATURE}

$$
\begin{aligned}
& A=\text { area of injection pattern, sq } \mathrm{ft} \\
& a, b=\text { Iimits of integration for Brigham and Smith's solution inte- } \\
& \mathrm{C}=\text { overall tracer concentration measured in producing well, } \\
& \text { parts per million } \\
& C_{j}=\text { tracer concentration of fluid from layer } j \text { as it enters pro- } \\
& \text { ducing wellbore, ppm } \\
& \begin{aligned}
\mathrm{Cmp}_{j}= & \text { 1ayer } \mathrm{j}^{\prime} \mathrm{s} \text { peak tracer concentration in the reservoir in the } \\
& \text { vicinity of the producing well, ppm }
\end{aligned} \\
& C p_{i}=i t h \text { concentration peak in the overall field data, ppm } \\
& \left(\frac{C_{j}}{C_{j}{ }_{j}}\right)_{i}=\begin{array}{l}
\text { dimensionless concentration ratio for } 1 \text { ayer } j \text { when the } i t h \\
\text { peak in the field data arrives at the producing well }
\end{array} \\
& \mathrm{F}_{\mathrm{D}}=\text { fraction of displacing fluid in the producing stream } \\
& h_{j}=\text { thickness of layer } j, f t \\
& i=\text { total injection rate in pattern area, any consistent units } \\
& i_{j}=\text { injection rate into layer } j \text {, any consistent units } \\
& \mathrm{K}=\text { dispersion coefficient, } \mathrm{ft}^{2} / \mathrm{sec} \\
& k_{j}=\text { permeability of layer } j \text {, any consistent units } \\
& L=\text { distance between injector and producer, } \mathrm{ft} \\
& \mathrm{m}=\text { total weight of tracer injected, lbs } \\
& \mathrm{m}_{j}=\text { weight of tracer injected into layer } j, 1 \mathrm{bs} \\
& \mathrm{n}=\text { number of layers } \\
& \mathrm{PV}_{j}=\text { displaceable pore volumes injected into layer } j \\
& \begin{aligned}
& P V_{p}=\text { pore volumes injected when peak in dimensionless solution } \\
&(\mathrm{C} / \mathrm{Cmp}) \text { occurs }
\end{aligned} \\
& \mathrm{Q}=\text { volumetric injection rate, } \mathrm{ft} \mathrm{t}^{3} / \mathrm{sec}-\mathrm{ft}
\end{aligned}
$$




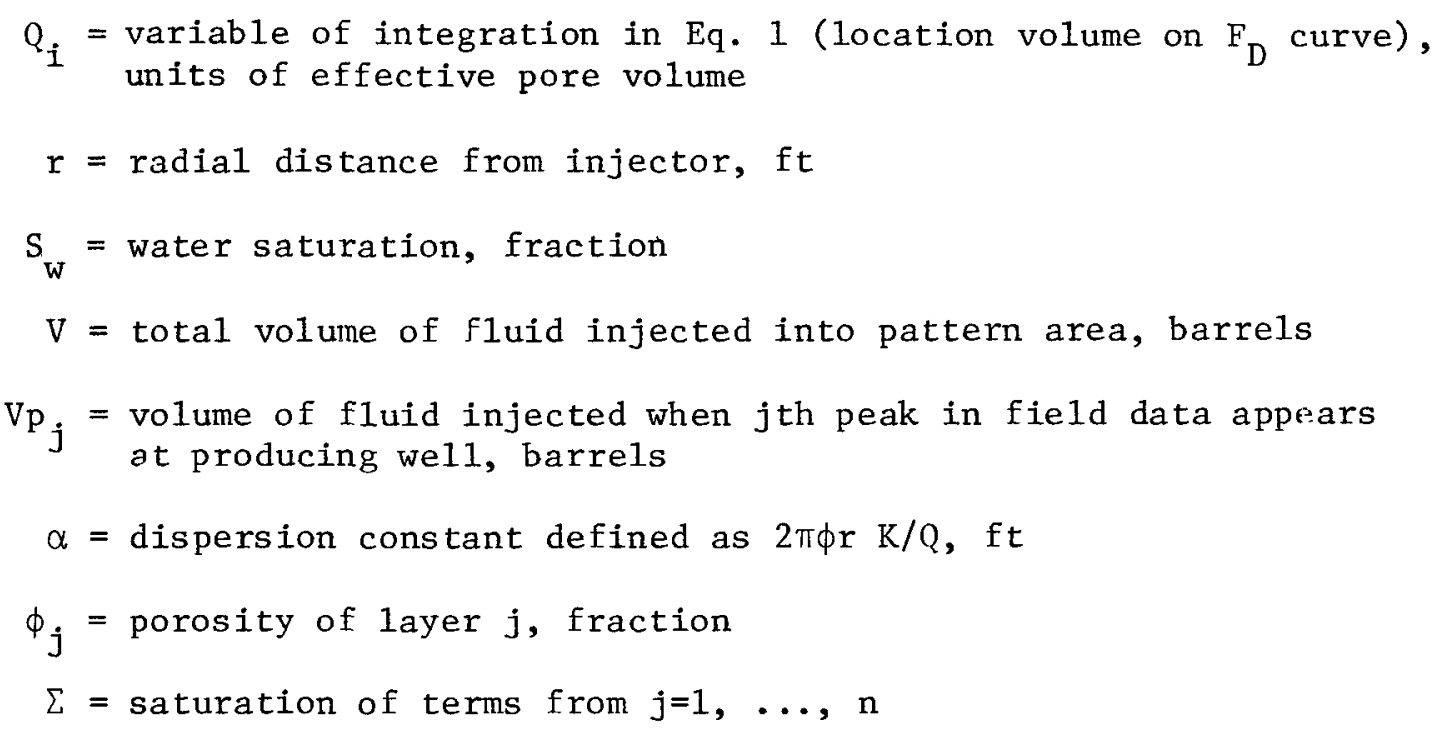


1. Brigham, W.E., and Smith, D.H.: "Prediction of Tracer Behavior in Five-Spot Flow," Paper SPE 1130, presented at the SPE-AIME 40 th Annual Fal1 Meeting, Denver, Colorado, Oct. 1965.

2. Wagner, O.R.: "The Use of Tracers in Diagnosing Interwe11 Reservoir Heterogeneities--Field Results," Paper SPE 6046, presented at the SPL-AIME 51st Annual Fal1 Meeting, New Orleans, Oct. 1976.

3. Baldwin, D.E., Jr.: "Prediction of Tracer Performance in a Five-Spot Pattern," J. Pet. Tech. (Apr. 1966), 513-517.

4. Raimondi, P., Gardner, H.F., and etrick, C.B.: "Effect of Pore Structure and Molecular Diffusion on the Mixing of Miscible Liquids Flowing in Porous Media," Paper No. 43, presented at the AIChE-SPE Joint Symposium on Fundamental Concepts of Miscible Displacement, Part II, San Francisco, Dec. 1959. 


\section{APPENDIX A}

\section{"PREDICTION OF TRACER BEHAVIOR IN FIVE-SPOT FLOW" \\ by W. E. Brigham and D. H. Smith}

Note: This paper was originally written assuming diverging radial flow between the injection and producing wells. The handwritten equations are the revisions later made by $W$. E. Brigham to account for diverging-converging radial flow. 


\title{
PREDICTION OF TRACER BEHAVIOR IN FIVE-SPOT FLOH
}

\author{
By
}

W. E. Brigham, Member AIN, and D. H. Smith, Jr. Hember ADE, Continental $0 i l$ Co., Ponca City, Okla.

Publication Rights Reserved

\section{ABSTRACT}

Equations are developed to predict the time of tracer breakthrough, the peak concentration of the tracer, and the general form of the brakthrough curve in a 5-spot flood. It is shown that these results depend on the amount of stratification of the reservoir, the volumes injected and produced, the natural dispersion coefficient of the tracer in the reservoir, the amount of tracer injected, plus all the reservoir volume parameters (i.e. well spacing, porosity, thickness).

Many laboratory data axe available on the breakthrough characteristics of a 5-spot flood, also much data is available on the natural linear dispersion coefficients of reservoix rock. To derive the equations, these data were conbined and several assumptions were made. It was also necessary to graphically differentiate the breakthrough data. Thus it should be recognized that the final equations likely have sone error. However, this should not invalidate their use, for the method and logic behind the derivation are sound, and thus the form of the final equations should be close to correct. In this paper, the prediction equations are used in a reverse sense. That is, the detailed tracer production history fron a field test is used to estimate per-cability variation in a 5-spot.

\section{IITRODUCTION}

Tracers have been used for many years in reservoir floods to help the operating engineex understand the flow characteristics. Generally this use has been entirely qualitative. The results of time-of-flight, peak concentrations at the producing wells, concentration history, and directional flow have beer used only to substantiate that channelling does nor does not exist. No attempts have been made to predict quantitatively the tracer breakthrough behavior that might be expected from different reservoir characteristics.

In the past couple of years it has become apparent that some prediction technique could be well used to supplement the other tools available to the reservoir engineer. It is becoming increasingly important that maxinum recovery be obtained from a flood, and any quantitative information about the reservoir can be of help in achieving this maximum. The work reported here is a step in this direction -- an attempt to quantify the tracer behavior.

Equations are developed to predict the time of tracer breakthrough, the peak concentration of the tracer, and the general form of the breakthrough curve in a 5-spot flood. Tracer production history from a field test are compared to the behavior as predicted by the equations. As nore field data become available, and more sophisticated derivations are made, the equation constants can be adjusted and better predictions and 
interpretations will be possible in the future.

These calculations were directed for use of tracers where the mobility ratio is near unity. In general, this is valid in many vaterfloods and almost all gas cycling projects. The method of approach, however, can be used whenever the reservoir coverage and dispersion characteristics can be approxinated. In systems where the mobility ratio is inherently unfavorable and fingering is predominant, the approach cannot yet be used because of the limited knowledge of dispersion in these systems. Thus, at present, this approach would be only partially successful in miscible flooding calculations.

\section{DEVELOPNENT OF EQUATIONS}

This section of the paper covers the method of calculating tracer behavior in a homogeneous 5-spot system when the mobility ratio is $1: 1$. Two characteristics affect the breakthrough history of the tracer; the mixing due to dispersion, and the pattern sweep efficiency.

These effects are treated separately and then mathematically combined.

\section{Dispersion or Mixing}

When one material miscibly displaces another in a porous medium, mixing occurs in a manner similar to Fick diffusion, except the constant of mixing is changed. In radial flow this equation can be expressed as follows:

$$
\frac{\partial C}{\partial x}+\frac{2 \pi \varphi x}{Q} \quad \frac{\partial C}{\partial t}=\frac{2 \pi \partial x K}{Q} \quad \frac{\partial^{2} c}{\partial r^{2}}
$$

where $\mathbf{C}=$ Concentration (any consistent units)

$\mathrm{K}=$ Dispersion coefficient - analogous to the Fick diffusion coefficient $(\mathrm{ft} / \mathrm{sec})$

$r=$ Radius ( $f t$ )

$t=$ Time (sec)

$Q=$ Volumetric injection rate $\left(\mathrm{ft}^{3} / \mathrm{sec}-\right.$ $f t$ )

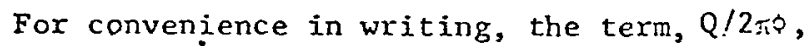
can be called $Q^{*}$. Another simplification can be made if the dispersion coefficient is assumed proportional to velocity. Experimeptal evidence shows this is a close approximation. Then the term, $2 \pi$ \% rK/Q (or $r K / Q^{\prime}$ ), can be replaced by $\alpha$ (a constant for any given porous medium). The resulting equation is

$$
\frac{\partial C}{\partial r}+\frac{r}{Q^{\prime}} \quad \frac{\partial C}{\partial t}=\alpha \frac{\partial^{2} C}{\partial r^{2}}
$$

Raimondi et $a 1^{2}$ have shown that this equation can be solved if one realizes that the term on the right hand side of the equation is quite small compared to the other terns. The value of the second partial can then be approximately calculated by assuming the right hand side is zero.

$$
\frac{\partial C}{\partial r}+\frac{r}{Q^{\prime}} \frac{\partial C}{\partial t} \cong 0
$$

The expression for the second partial then becomes,

$$
\frac{\partial^{2} c}{\partial x^{2}} \cong \frac{-1}{Q^{\prime}} \quad \frac{\partial c}{\partial t}+\frac{r^{2}}{\left(Q^{\prime}\right)^{2}} \quad \frac{\partial^{2} c}{\partial t^{2}}
$$

and Equation 2 can be replaced by,

$\frac{\partial \mathrm{C}}{\partial \mathrm{r}}+\frac{\mathrm{r}}{\mathrm{Q}^{r}} \frac{\partial \mathrm{C}}{\partial \mathrm{t}} \cong-\frac{\alpha}{\mathrm{Q}^{\prime}} \frac{\partial \mathrm{C}}{\partial \mathrm{t}}+\alpha{\frac{\mathrm{r}}{\mathrm{Q}^{1}}}^{2} \frac{\partial^{2} \mathrm{C}}{\partial \mathrm{t}^{2}}$

In Equation 5 there are two multipliers on òc/ot: $r / Q$ and $\alpha / Q^{\prime}$. Experimental data on C (Ref. 1) shows that it is always considerably smaller than one foot; so it can properly be neglected compared to $r$, and Equation 5 can be simplified to:

$$
\frac{\partial C}{\partial r}+\frac{r}{Q^{1}} \frac{\partial C}{\partial t}=o\left(\frac{r}{Q^{1}}\right)^{2} \frac{\partial^{2} C}{\partial t^{2}}
$$

The equation can be further simplified by changing variables.

Define:

$$
\begin{aligned}
& \tau=t-\frac{r^{2}}{2 Q} \\
& \rho=\frac{r^{3}}{3}
\end{aligned}
$$

The resulting expression is:

$$
\frac{\partial \mathrm{C}}{\partial \rho}=\frac{\alpha}{Q^{2}} \quad \frac{\partial^{2} \mathrm{C}}{\partial \tau}
$$

When one fluid is displacing enother in an infinite, radial porous medium, the solution to Ecuation 7 is:

$$
\begin{aligned}
\frac{c}{C_{0}} & =\frac{1}{2} \operatorname{erfc}\left(\frac{\tau}{2 \sqrt{\sigma_{\rho} / Q^{\prime}}}\right) \\
& =\frac{1}{2} \operatorname{erfc}\left(\frac{Q^{\prime} t-x^{2} / 2}{3 \frac{\operatorname{ar}^{2} / 3}{3}}\right)
\end{aligned}
$$


When a tracer is injected, it is necessary to include both the front and back edges of the tracer slug. The solution will then contain two terms of the form similar to Equation 8. For symmetry it is convenient to have the reference point at the middle of the tracer siug. If the tracer is injected for a time, $t_{1}$, the reference points will be at $t \pm t_{1} / 2$, and the result is;

$$
\begin{aligned}
\frac{c}{C_{0}} & =\frac{1}{2} \operatorname{erfc}\left(\frac{Q^{\prime}\left(t+t_{1} / 2\right)-r^{2} / 2}{2{\sqrt{\alpha r^{3}} / 3}^{3}}\right) \\
& -\frac{1}{2} \operatorname{erfc}\left(\frac{Q^{\prime}\left(t-t_{1} / 2\right)-r^{2} / 2}{2 \sqrt{\alpha r}^{3} / 3}\right)
\end{aligned}
$$

We wish to know the peak concentration, or midpoint concentration, $C$, of the tracer slug. At this point $Q^{\prime}{ }^{\prime} P^{\prime}{ }^{2} / 2$, and the result is,

$$
\frac{c_{m p}}{c_{0}}=\operatorname{erf}\left(\frac{Q^{\prime} t_{1}}{4{\sqrt{\alpha r^{3}} / 3}^{3}}\right)
$$

The term $Q^{\prime} t$, is a measure of the amount of tracer injected. For easier visualization of the variables it might be simpler to look at this term in relation to a width of tracer slug. If the slug moved out into the reservoir without mixing, its undiluted "width", W, would be expressed as $\mathrm{rW}=\mathrm{Q}^{\prime} t_{1}$, and Equation 10 could be written,

$$
\frac{c_{m p}}{c_{o}}=\operatorname{erf}\left(\frac{\sqrt{3} w}{4 \sqrt{\alpha r}}\right)
$$

By comparison, for dispersion of a tracer in a linear flow for a distance, $L$, the result is,

$$
\frac{c_{m p}}{c_{0}}=\operatorname{erf}\left(\frac{w}{4 \sqrt{\alpha L}}\right)
$$

so the radial and 1 inear equations differ only in the factor $\sqrt{3}$.

When the argunent of the error function is less than about 0.1 , the function becomes linear, with the constant 1.13. In tracer work, the desired output concentration is almost always less than one tenth of the input concentration, so Equation 11 can be simplified to,

$$
\frac{\mathrm{c}_{\mathrm{mp}}}{\mathrm{C}_{\mathrm{o}}}=\frac{1.13 \sqrt{3} \mathrm{~W}}{4 \sqrt{\alpha \cdot \mathrm{r}}}
$$

Flow in a 5-spot is not radial, but it is possible to approximate the geometry of a 5spot system with a radial model. If a circle is drawn with its center at the injection well and the circumference cutting the four surrounding producing wells, and then the circle is folded back on itself as shown in Figure 1, the shape of the front is very similar to the actual front in a 5-spot displacement at breakthrough. Of great importance is that the length of the front thus formed is very close to the length of the actual front in 5-spot flow. And a study of Equation 13 shows that the front length is the most important parameter affecting the mid-point concentration.

The mass of tracer injected is equal to the perimeter times: width, height, porosity saturation, concentration and density. For a waterflood tracer this is

$$
m=2 \pi L V h \oplus S_{w} C_{o}(62.4)
$$

$$
\text { Where } \begin{aligned}
L= & \text { Distance from injector to } \\
& \text { producer ( } \mathrm{ft} \text { ) } \\
\mathrm{C}_{0}= & \begin{array}{l}
\text { Injected concentration } \\
\text { (weight fraction) }
\end{array}
\end{aligned}
$$

Equations 13 and 14 can now be combined to determine the amount of tracer to inject for a desired peak concentration, remembering that $r$, in Equation 13 is now the intervell distance, L.

$$
m=800 h \geqslant S_{w} c_{m p} L^{1.5} \alpha^{-5}
$$




\section{Areal Sweep Elfects}

Equation 15 gives us the concentration of the tracer flowing in the reservoix. However, this is not the same as the concentration flowing out of the wellbore, for the seometry of the 5-spot system causes the tracer front to be diluted at the vellbore. This can be explained as follows.

Assume we have a homogeneous 5-spot filled with fluid " $A$ " and inject fluid " $B$ " which has the same mobility. Also assume no mixing takes place at the front (later the areal sweep effects vill be combined with the mixing effects). Thus " $B$ " is injected as a sharp front and will remain as a sharp front. The resulting breakthrough curve looks like curve, 1 , in Figure 2a. Note that the percent " $B$ " rises after breakthrough, but it requires a large injection volume before the producing concentration climbs to 100 percent " $B$ ". The " $B$ " that is flowing in the reservoir, however, is at 100 percent concentration.

Now consider a case where a slug of " $B$ " is injected and this in turn is followed by " $A$ ". Again assume no dispersion occurs and slug " $B$ " remains sharp and undiluted. The breakthrough curve for the front of the " $B$ " slug will remain the same, and the breakthrough curve for " $A$ " following " $B$ " will be identical in shape-merely lagging the first curve as shown in curve 2, Figure 2a. At any point in the production history, the concentration of " $B$ " being produced is equal to the vertical distance in the " $B$ " area of Figure $2 a$, and the resulting "B" concentration production curve looks like Figure $2 b$. Notice that the peak producing concentration of " $B$ " is considerably less than 100 percent, even though the concentration of " $B$ " flowing in the reservoir is 100 percent.

When the tracer becomes dispersed (or mixed) in the reservoir it is convenient to think of the tracer being composed of many small slugs, each with a different concentration. The highest concentration is in the center and progressively lower values are ahead and behind. This concept is shown in Figure 2c. In this case the " $B$ " output concentration curve can be calculated by vertically suming the concentration contributions of each small segment, and the resulting curve looks something like Figure $2 \mathrm{~d}$. The general shape of this curve is similar to the undiluted slug of Figure $2 \mathrm{~b}$, but it is less sharply peaked; and, of course, has a lower concentration due to the mixing.

The problem now is to develop these qualitalive concepts into numbers and equations. For the 5-spot areal sweep information the data of Dyes, Caudle, gnd Erickson ; Caudle and Witte ${ }^{4}$; and Fay and Prats were used. Since these data differed slightly from each other, they were averaged and the resultant curve plotted in Figure 3. This curve could not be conveniently fit to an equation, so it was differentiated graphically, plotted as the solid stair-step line of Figure 4, and emperically fit to the following equation.

$$
\begin{aligned}
\log \left[\log \left(\frac{1.07}{1.07-F_{D}}\right)\right]= & -.0410+.581 \log \left(Q_{i}-.72\right) \\
& \text { for } .72<Q_{i}<2.29
\end{aligned}
$$

$$
\begin{aligned}
& \text { Where } F_{D}= \\
& \begin{aligned}
& \text { in the producing stream } \\
& Q_{i}= \text { Volume injected and produced } \\
& \text { (effective pore volumes) }
\end{aligned}
\end{aligned}
$$

This is plotted as the dashed line of Figure 4.

\section{Combining the Breakthrough and Dispersion Data}

Equations 11 or 13 predict the concentration at the midpoint, but the concentration ahead of and behind the midpoint is also needed. This is an $\mathrm{e}^{-\mathrm{x}^{2}}$ type term, which can be extracted from Equations 11 or 13 as follows,

$$
\begin{aligned}
\frac{c_{1}}{c_{m p}}=e^{-} & \frac{3(\Delta r)^{2}}{L \alpha L} \\
\text { Where } c_{1} & =\text { Concentration at some point } \\
\Delta r & =r_{1} \text { near the midpoint, } L
\end{aligned}
$$

Since Equation 16 is in pore volume units, and we wish to combine it with Equation 17, it will be necessary to change Equation 17 to pore volume units. The volume of a tracer segment is $2 \pi \phi \Delta L \mathrm{Lh}$ and one pore volume is $20 \mathrm{~L}^{2} \mathrm{~h}$, so an increment in pore volume is,

$$
\Delta(\mathrm{PV})=\frac{2 \phi \pi \Delta x \mathrm{Lh}}{20 \mathrm{~L}^{2} \mathrm{~h}}=\frac{\pi \Delta \mathrm{r}}{\mathrm{L}}
$$

and the concentration profile becomes,

$$
\frac{c_{s}}{c_{m p}}=e^{-\frac{3 L(\Delta P V)^{2}}{4 \pi^{2} \alpha}}
$$

Assume now that a tracer slug has been injected, it is followed by a volume of water $\left(V_{i}\right)$ and the midpoint of the tracer is along the front at $V_{.}$. Equation 19 states that the tracer is distributed everywhere in the reservoir at a concentration proportional to e-( $\triangle P V)^{2}$. According to Equation 16, any tracer at a location 2.29 or more pore volumes out from the injection well will have already been produced, and any tracer 
not yet started to be produced. The rest of the tracer is being produced at a rate depending on its location. To determine the total tracer production it is necessary to sum all contributions from .72 to 2.29 pore volumes, thusly.

$$
\begin{aligned}
\frac{C\left(V_{i}\right)}{C_{m p}}=\int_{.72} \frac{d F_{D}}{d Q_{i}} & e^{-\frac{3 L\left(Q_{i}-V_{i}\right)^{2}}{4 \pi^{2} \alpha}} d_{i} \\
\text { Where } C\left(V_{i}\right) & =\begin{array}{l}
\text { Producing concentration as a } \\
\text { function of volume injected. }
\end{array} \\
F_{D} & =\text { Fraction displacing fluid. } \\
V_{i}^{D} & =\text { Volume injected (pore volumes). } \\
Q_{i} & =\text { Location volume (pore volumes). }
\end{aligned}
$$

This is the same "summing" used earlier to get from Figure $2 c$ to Figure $2 d$.

Unfortunately, Equation 20 cannot be integrated analytically due to the complex relationship between $F_{D}$ and $Q$; so it was integrated numerically, giving $C$ versus $V_{i}$ for various values of $\mathrm{L} / \alpha$. The results of these calculations are plotted in Figure 5. Note that, for all spacings and dispersion coefficients, the peak concentration producing from the well is considerably less than the peak concentration in the reservoir.

The peak concentrations of Figure 5 were plotted on $\log -\log$ paper in Figure 6 . Emperically they were found to fit a straight line with the following equation.

$$
\frac{c_{p}}{c_{m p}}=2.63\left(\frac{L}{c}\right)-.235
$$

$$
\text { Where } C_{p}=\begin{aligned}
& \text { Peak concentration produced } \\
& \text { from the reservoir. }
\end{aligned}
$$

Equation 21 can now be combined with Equation 15 to give us a working equation for 5-spot geometry.

$$
\mathrm{m}=304 \mathrm{~h} \phi \mathrm{S}_{\mathrm{W}} \mathrm{C}_{\mathrm{p}} \alpha^{.265 \mathrm{~L}^{1.735}}
$$

For convenience, it is easier to use the concentration, $C_{\text {, }}$, in parts per million. This is the usual method of expressing tracer concentration. The inter-well distance is more easily handled in hundreds of feet. With these changes, the equation becones,

$$
m=.90 h \geqslant S_{w} C_{P} \alpha^{.265} L^{1.735}
$$

$$
\begin{aligned}
\text { Where } C_{\mathbf{P}}= & \text { Peak concentration producing } \\
& \text { from the well (ppm) } \\
\mathrm{L}= & \text { Distance from injector to } \\
& \text { producer (hundreds of feet) }
\end{aligned}
$$

Effect of Outside Wells

Only the flow in the pattern has been included so far in the calculations. In a developed 5-spot pattern, each producing vell receives fluids fron four wells. Thus, if the pattern is balanced, the tracer is further diluted by a factor of four.

If the pattern is not balanced, the flow system is not so simple, for the basic sveep pattern will be changed from that used to arrive at Equation 23. The effect of the sweep pattern change cannot be properly calculated pecause data are not available. However, the equations can be partially corrected by accounting for the total volumes injected and produced. This is show in the following example.

For instance, assume that an injection well is taking $1000 \mathrm{~B} / \mathrm{D}$, and it is surrounded y four producers making $600 \mathrm{~B} / \mathrm{D}$ each. If the reservoir is liquid filled and there is dynamic balance of flow, each producer vill get $250 \mathrm{~B} / \mathrm{D}$ from the injector and $350 \mathrm{~B} / \mathrm{D}$ From outside the pattern. Thus the actual peak concentration is smaller than calculated from Equation 23 by the ratio $250 / 600$.

If the pattern is balanced, each producer Will make $1000 \mathrm{~B} / \mathrm{D}$. Each producer will be getting $250 \mathrm{~B} / \mathrm{D}$ from the injector and 750 $B / D$ from ouiside the pattern. The peak concentration will be smaller by the ratio $250 / 1000$.

These examples illustrate the idea, but they are considerably simpler than the usual field case.

\section{Stratification of Reservoir}

All the previous calculations were based pn a homogeneous reservoir. Unfortunately, puch does not exist. But it is possible to hake some allowance for the heterogeneity of the actual reservoir with sone further assumptions.

One of the most comron methods of handling inhomogeneity is to mathematically divide the feservoir into layers, assign a permeability to each layer, and assume no cross flow. Tie should hot believe these assumptions too wholeheartedly, put this model has a history of passable regervoir predictions to back up its usage. 
If a reservoir is divided into layers, the amount of tracer going into each layer is proportional to its permeability. So, from Equation 15, the concentration flowing in that layer will also be proportional to its permeability. At the producing wellbore the tracer from a given layer vill be diluted by flow coring in from other layers. The dilution is proportional to the $\mathrm{kh}$ product of the layer compared to the total $\mathrm{kh}$ of the reservoir. So the resulting producing concentration is as follows

$$
c_{i}=c_{p} \frac{k_{i}}{k_{\text {avg }}}\left(\frac{h_{i} k_{i}}{\sum h_{i} k_{i}}\right)=c_{p} \frac{h_{i}}{h}\left(\frac{k_{i}}{k_{\text {avg }}}\right)^{2}
$$

$c_{i}=$ Concentration peak from the ith layer $\mathrm{C}_{\mathrm{p}}^{i}=$ Peak concentration if the reservoir is homogeneous (from Equation 23)

$k_{i}=$ Permeability of the ith layer

$k{ }^{i}=$ Average permeability of the reservoir

avg $=$ Height of the ith layer

$\hbar=$ Height of the reservoir

Since the flow rate through the ith layer is proportional to its permeability, the time to breakthrough of that layer is inversely proportional to its permeability, as follows.

$$
t_{i}=t_{\text {avg }} \frac{k_{\text {avg }}}{k_{i}}
$$

Where $t_{i}=$ Time to breakthrough of the $i$ th layer

$\begin{aligned} & t_{\text {avg }}= \text { Time to breakthrough of the } \\ & \text { homogeneous reservoir }\end{aligned}$

When Equations 23, 24 and 25 and Figure 5 are used in conjunction with the effect of the outside wells, the peak concentration, the concentration profile, and breakthrough time of each layer can be calculated for any given 5-spot condition. In actual practice the contribution from the most permeable layer, or layers, will be most important.

\section{FIVE-SPOT FIELD TEST}

A $21 / 2$ acre inverted 5 -spot having approximately 12 feet of net pay was chosen for a test. The average porosity was 26 percent and water saturation was 55 percent. From core data, the average air permeability of the sand was $1500 \mathrm{md}$ with indications of a $5000 \mathrm{md}$ streak approximately one foot thick. Laboratory mixing data on the core gave an $\alpha$ of $0.05 \mathrm{ft}$. The orientation of the pattern wells is shown in Figure 7. Further data on the test is given in Reference 6.

Two hundred pounds of amoniun thiocyanate and 150 pounds of potassium iodide were injected simultaneously as tracers. During the test, the injection well averaged 600 BWPD and the producing rates were as follows: Well A, 260 EWPD; We11 B, 160 BWPD; Well C, 140 BISPD; and Well D, 240 BWPD; for a total of 800 BI.PD. The data on breakthrough of the tracers is shom in Figures 8,9 and 10 for Wells $A, C$ and $D$. No tracer was ever detected from Well B.

Since no tracer was found in Well $B$, it was assumed that only fifty barrels per day of the injected watex were moving toward this well. The remaining water was distributed among the other three wells according to their production rate; Well A 225 BWPD, Well C 120 $B W P D$, and hell $D 205 \mathrm{BWPD}$. The total tracex produced from these wells indicates that this assumption is sound, for about equal volumes were produced from Wells $A$ and $D$ with considerably less from We11 C.

The amnonium thiocyanate curve of hell $D$ was chosen for detalled analysis. Since the injection well was down for about four days, it was felt that it would be meaningless to attempt to match the concentration curve during and after that period. So the tracer elution curve was approximated from the period of 2000 bbls to 4000 bbls production using Equations 23, 24 and 25 and Figure 5. The resulting match is shown in Figure 11 .

Three permeable streaks were used to arrive at Figure 11: $4110 \mathrm{md}, 0.99 \mathrm{ft}$ thick; $3420 \mathrm{md}, 1.00 \mathrm{ft}$ thick; and $2980 \mathrm{md}, .59 \mathrm{ft}$ thick. Notice that the shape of the curve is quite close to the thiocyanate curve of Figure 10. Although the detailed spikes and peaks are missing, the curve basically consists of two major peaks as shown. On the other hand the potassium iodide curve of Figure 10 is basically a single broad hump covering the sampe production interval as the thiocyanate. So the "double peak" approximation of Figure 11 is not valid for the iodide. Since the pexcentage of iodide and thiocyanate recovered was virtually the same in all three wells, we must conclude the iodide curve is as valid as the thiocyanate curve. Rather than emphasizing the exact values calculated for the permeability streaks of Figure 11, the curves should be considered in a broader sense to conclude there is a zone about $21 / 2$ feet thick which ranges from about 2 to 3 times the average permeability.

Since the curves for Well A are similar to Well $D$, the conclusions should be the same for this quadrant.

The injection well was down during the period when Vell $C$ was peaking out. Since this undoubtedly disrupted the flow pattern (notice the drop in tracer concentration in all three wells during this pericd), no analvsis 
was attempted on We11 C.

It is obvious that a Northwest-Southeast permeability trend exists in this pattern. This could possibly have been expected from the differing production rates of the four wells; but it was dramatically pointed out by these tracer results. This is especially interesting in view of the fact that the core analysis data indicated no such permeability trend.

\section{CONCLUSIONS}

Equations have been derived for use in predicting tracer flow behavior in reservoirs. the specific equations were developed to handle 5-spot flow of water tracers at a $1: 1$ mobility ratio. Although these conditions limit the scope of the equations; the method of approach is general enough to be used wherever areal coverage, dispersion and flow pattern is known or can be approximated.

Using the equations and the detailed tracer production history, the degree of stratification in a reservoir can be calculated.

The field test data indicate that the stratification and producing concentration values calculated from these equations are realistic, giving some confidence in the use of these equations in reservoir analysis.

\section{ACKNOWLEDGEMENT}

The authors wish to thank the management of Continental oil Company for permission to publish this paper, and the members of Continental's Production Research Division for their advice and stimulating discussions on the ideas presented in the paper.

\section{NONENCLATURE}

$\mathrm{C}=$ Concentration (any units are permissible as long as they are consistent - genera11y weight fraction or ppm are used)

$c_{i}=$ Peak concentration due to flow from the ith layer

$c_{1}=$ Concentration at $r_{1}$, near the midpoint L

$c_{0}=$ Injected concentration

$c^{0}=$ Peak concentration flowing from a homogeneous reservoir

$C\left(V_{i}\right)=$ Producing concentration as a function of volume injected $\left(V_{i}\right)$

$F_{D}=$ Fraction of displacing fluid in the producing stream

$h=$ Height of reservoir ( $f t)$

$h_{i}=$ Height of the ith layer ( $f t$ )

$K=$ Dispersion coefficient for miscible displacement in a porous medium $\left(\mathrm{ft}^{2} / \mathrm{sec}\right)$

$\mathrm{K}_{\mathrm{av}_{b}}=$ Average permeability of the reservoir $k_{i}=$ Permeability of the ith layer (nd)

$L=$ Total length of displacement, also distance from injector to producer ( $f t$ )

$\mathrm{m}=$ Amount of vater tracer injected ( $1 \mathrm{~b}$ )

$P V=$ Effective pore volumes (dimensionless)

$Q=$ Volumetric injection rate $\left(\mathrm{ft}^{3} / \mathrm{sec}-\mathrm{ft}\right)$

$Q_{1}=Q / 2 \pi$

$Q_{i}=$ Location volume on the $F_{D}$ curve (effective pore volumes) ${ }^{\mathrm{D}}$

$\mathbf{r}=$ Radius (ft)

$\Delta r=L-r$

$r_{1}=$ Radius near the tracer midpoint, $L$, $(E t)$

$S_{w}=$ Vater saturation (fraction)

$t_{1}^{w}=$ Time for injection of a tracer slug ( $\mathrm{sec})$

$t_{i}=$ Time for breakthrough of the ith layer (sec)

$t_{\text {avg }}=$ Time for breakthrough of a honogeneous reservoir (sec)

$\mathrm{V}_{i}=$ Volume injected (effective pore volumes)

$W=$ Width of tracer slug ( $f t)$

$\alpha=$ Dispersion constant $r K / Q^{\prime}$ (ft)

$\phi=$ Porosity (fraction)

\section{REFERENICES}

(1) Brigham, W. E.; Reed, P. W. and Dew, J. N., "Experiments on Mixing During Miscible Displacement in Porous Media" SPE Jour. V1, No. 1, p 1 (March 19ó1).

(2) Raimondi, P., Gardner, H. F., and Patrick, C. B., "Effect on Pore Structure and Molecular Diffusion on the Mixing of Miscible Liquid Flor in Forous Media," Preprint 43 presented at the AIChE-SPE Joint Symposium on Fundamental Concepts of Mliscible Displacement, Part II, San Francisco (Dec. 6-9, 1959).

(3) Dyes, A. B., Caudle, B. H., and Erickson, R. A., "Oil Production after Breakthrough as Influenced by Nobility Ratio," Trans. AIIE (1954) 201, p 27.

(4) Caudle, B. H., and Witte, M. D., "Production Potential Changes During Sweep-Out in a FiveSpot System," Trans. AINE (1959) 216, p. 446.

(5) Fay, C. H., and Prats, M., "The Application of Numerical Nethods to $C_{y} c l$ ing and Flooding Problems," Proceedings from Third lorld Petroleum Congress, Section II, p. 555 (1951)

(6) Smith, D. H. and Brigham, W. E., "Field Evaluation of vaterflood Tracers in a FiveSpot" API Division of Production, Midcontinent District Meeting, Wichita, Kansas (March 31-Apri1 2, 1965) 


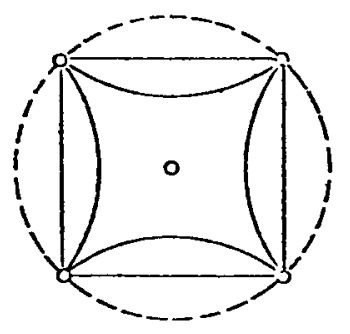

Figure 1 APPROEILIATIOV OF FIVE-SDOT GEONETRY USIAG E CIRCLE
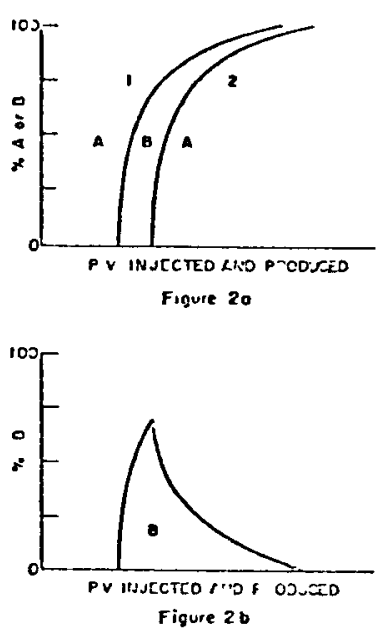

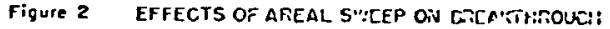

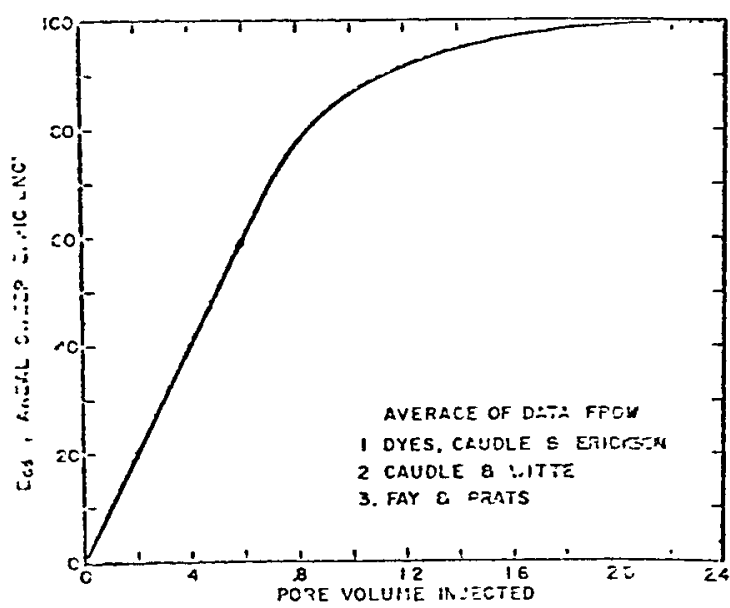



ODLLTT FITIO ,



Figure 4 5-SPOT CREAKTIIROUC:I CURVE



Figure 5 EFFECT OF SPACING ANO DISPERSION COSFFICIENT ON BAEAKTHQOUGH hISTOAT
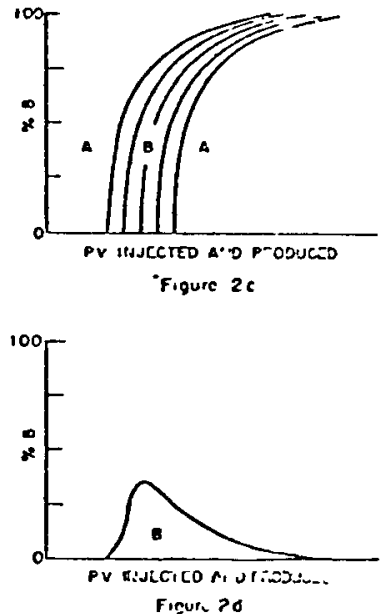
WELL "A"

$\triangle$

INJECTOR

WELL "C"

WELL " 0 "

TRACER TEST PATTERN

Figure 7

WELL " $B$ "

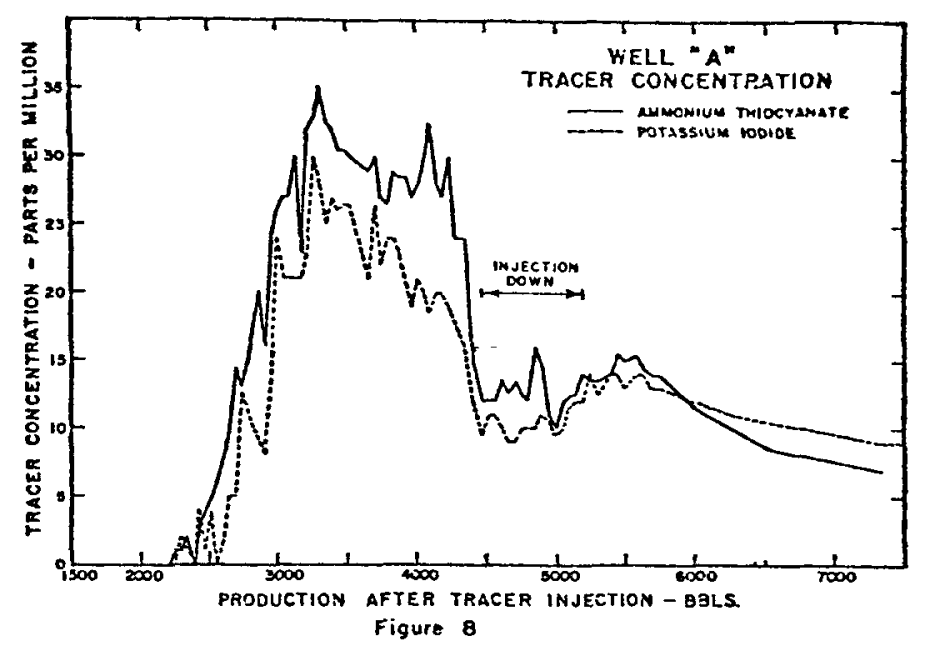

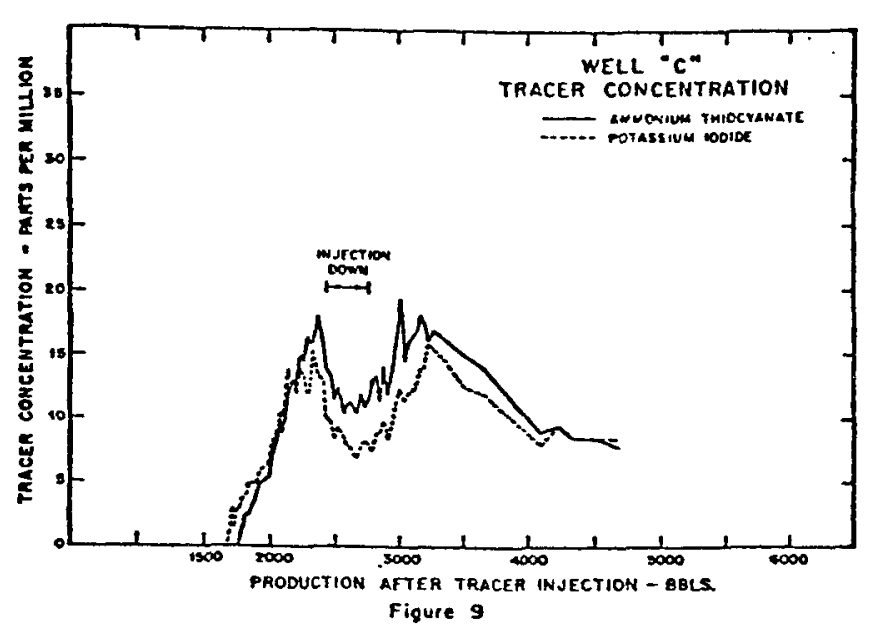
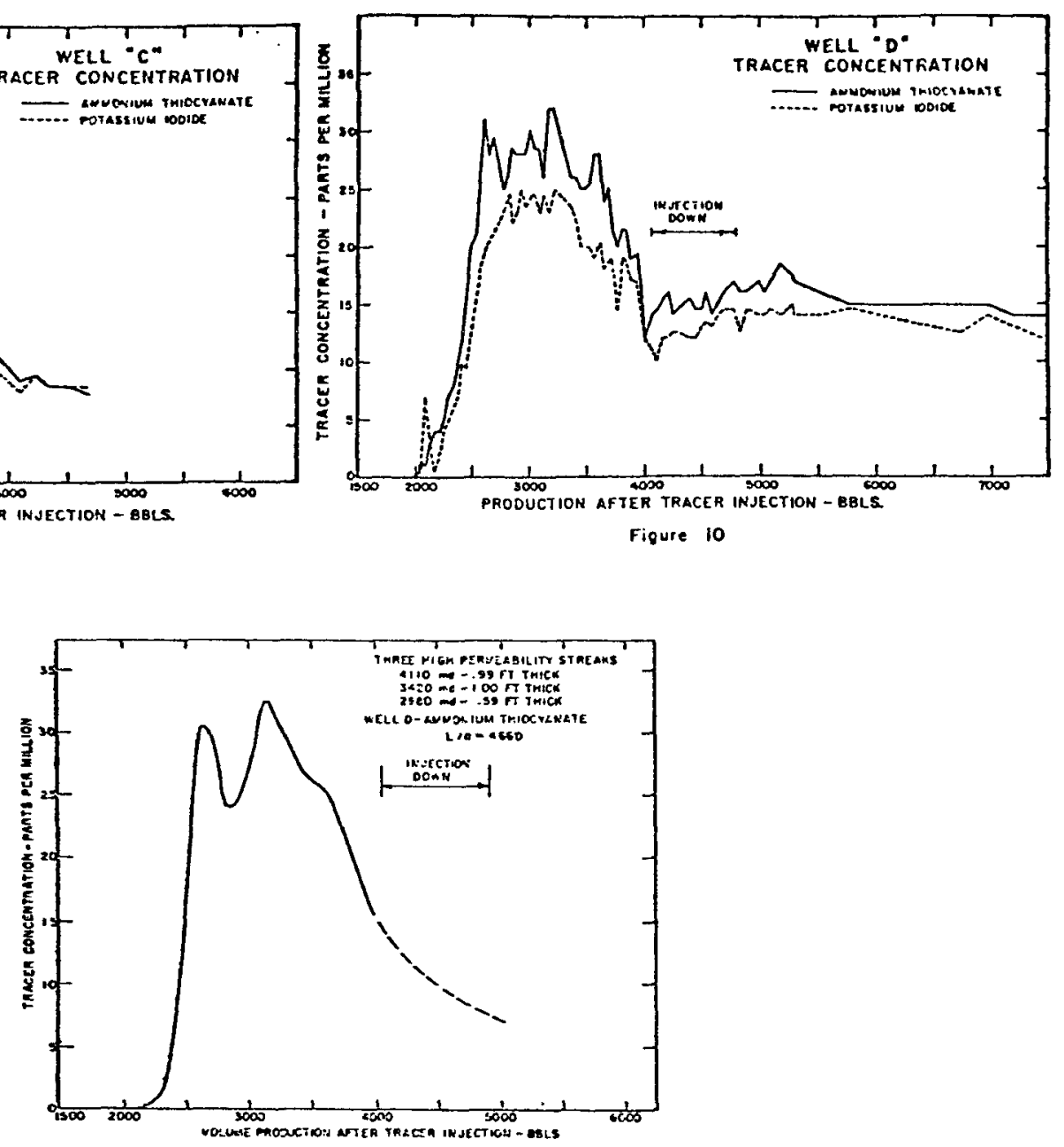

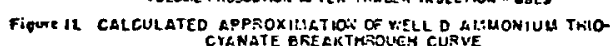




\section{APPENDIX B}

COMPUTER PROGRAM TO ANALYZE FIELD-TYPE DATA FROM

FIVE-SPOT TRACER TESTS TO DETERMINE THE DEGREE OF RESERVOIR LAYERING 
$$
\text { . }
$$ 


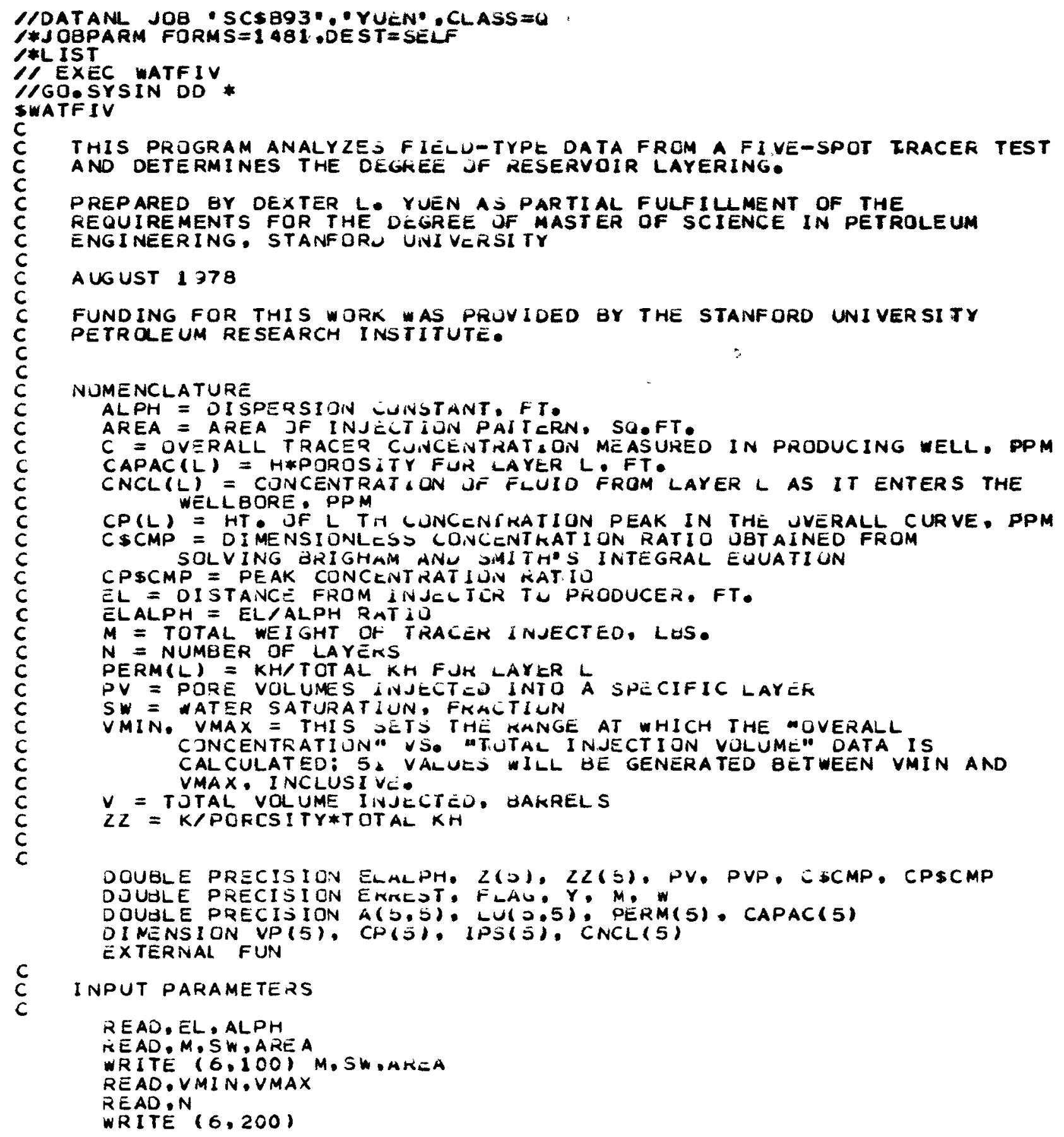

C INPUT PARAMETERS

READ, EL, ALPH

KEEAD, $M, S W, A R E A$

WRITE $(6,100)$ M, SW,AKEA

READ,VMIN,VMAX

WRITE $(6,200)$ 
OO I L $=1 \cdot N$

READ, VP(L),CP(L)

^RITE $(6.20:) L \cdot V P(L) . C R(L)$

- CONTINUE

$c$
$c$

CALCULATE CONSTANTS

$I D I M=N$

ELALPH = EL/ALPH

WRITE $(6,300)$ EL. ALFH,ELALPH

$Y=M / 1.0004 * S W *(E L * * 205) *(A L H H * * 05)$

$\stackrel{c}{C}$



(ALCULATE K/POKOSITY*TUTAL KII $(=Z Z)$

$002 L=$

$Z(L)=P V F / V P(L)$

$Z Z(L)=Z(L) * A R E A * O / 20040$

c

¿ CUNTINUE

DET UP MATFIX ELEMENTS

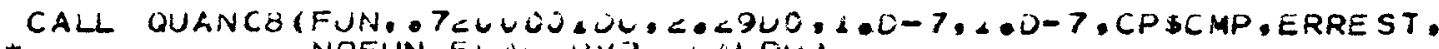

ofLAu orvP, CLALFHI

$D O 4 K=1: N$

IF (LOEQ:K) GOTO I

$P V=V P(L) * \angle(K)$

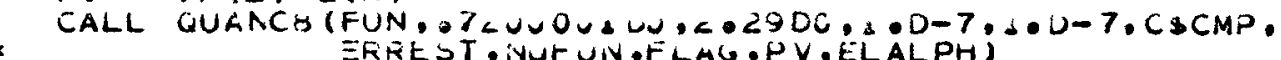

$A(L, K)=C \$ C M P * Y * \angle L C(K)$ WIV OFLAGOPV,ELALPHJ

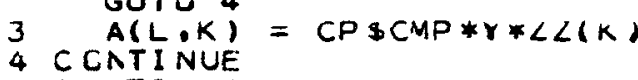

S CUNTINUE

$\underset{c}{C}$

SULVE MATRIX EQLATICIV TU ULT KH/TUTAL KH (=PERM)

CALL DECMPI (N. A,ID\&M,LU,IPS, C JO, E6O)

CALL SOLVEI (N.LU.I I

C CALCULATE H*POROSITY (=LAPAC)

WRITE $\left(6,4^{n O}\right)$

JO $\mathrm{O} L=2, N$

CAPAC (L) = OERM(L) $\angle L(L)$

O C CNTINUE

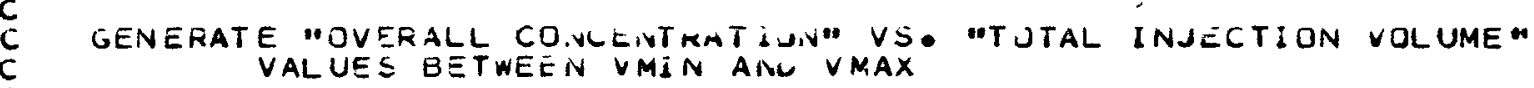

$\stackrel{c}{c}$






$$
\text { CONTINUE }
$$

THIS PRUgRAM EVALUATES THE INTEgRAL THAT UESCRIBES TRACEK CONCENTKATION AT THF PFOUUCING WELL AS A FUNCTIUN OF PORF VOLUMES INJECTED INTO A HOMUGENERUS RESERVUIR LAYEH. A FIVE-SPOT INJECTION PATTFRN IS ASSUMED

OUANCB WAS DBTAINED FROM IHE SOURCE LIBRARY AT THE STANFGRD CENTER FGR INFIIRMATICIN PKUCESSING

SUBROU II NE CUANC E(FUN, A, B. ABSERR, KELERR .KESULT, ERREST, NOFUN, FLAG. * $\checkmark 1 . E L A L P H)$

DOUBLE PRECISION FUN, A, B. AHSERR, RELERR, RESULT, ERRES , FLAG DOUBLE PKECISION VI.ELALPH INTEGFR NUFUN

ESTIMATE THE INTEGRAL UF FUN(X) FRTM A TO B

TO A USER NROVIDED TOLERANCE.

AN AUTOMATIC ADAPTIVE ROUTINE BASED ON

THE B-PANEL NEWTON-COTFS RULE.

INPUT ..

FUN THE NAME OF THE INTEGRANO FUNCTION SUBPROGRAM FUN(X). A THE LOWER LIMIT OF INTEGRATIUN.

A $B$ THE LOWER LIMIT OF INTEGRATIUN. RELERR A RELATIVE ERROR TOLFRANCE. (SHOULD BE NON-NEGATIVE) ABSERR AN ABSOLUTE ERR OR TOLERANCE. (SHOULD BE NON-NEGATIVE)

00000000 50000010 04000020 00000030 00000040 00000050 00000060 00006070 00000080 00000090 00000100 00000110 0000110 00013 0000130 00000140 00000150 0000160 crooc170 
RESULT AIV APPFUXIMATIUIV TU IHL \& NTEGKAL HOPEFULLY SATISFYING THE LEAST STFIVG_NT UT THC TWO ERRUR TOLERANCES.

ERREST AN ESTIMATE UF THE MAUIVITUUE OF THE ACTUAL ERRUR.

THE NUMHER IT FUILT LUIV VALUES USLO IN CMLCULATIUN UF FES SULT.00000230

FLAG

A RELIAB?LiTr AVU.LAIUK \& IF FLAG IS LEKU. THEV RESULT

PROEADLY SATLSFLEJ THE LKRUF TOLEKANCE. IF FLAG IS

XXX.YYY, THLA XAX = THE NUNBE

NUT COUVERGEU MIVU O,YYY = THE FHACTIUN JF THE INTERVAL

LEFT J UO AHLIN THL LIMAT UN NUFUN IAS APPROACHED.

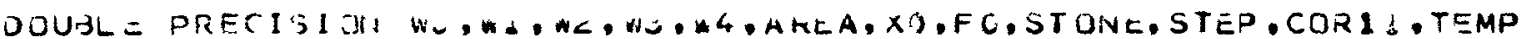



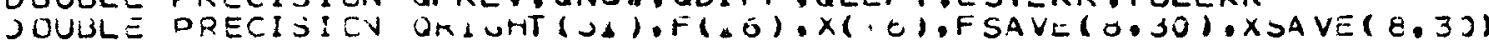

DOUBLE PAEC

INTEGER LEVMIV.LEVMAX,LEVUUT, NUMA A, VJFIN,LEV,NIM,I,J

\section{$* * *$ STAGE
SET CONSTANTS.}

MLINERAL DIVITIALIZATIUN

\section{LEVMIN $=1$ \\ LEVMAX $=30$ \\ NUMAX $=520$}

NOF IN = NOMAX * B* LLVVMAX-LEVUUT+L**(LEVOUTH\&))

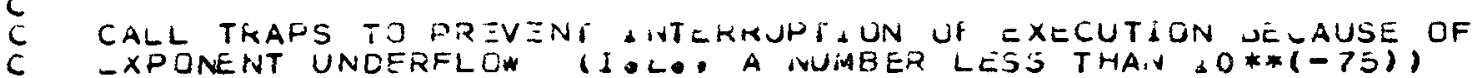

CALL TRAPSQ:.1.2JOJUUJUUJ,..1

C TRJUBLE WHEN NOF IN TIAUMES INUF 1 WY

wo $=3955030,1+4.400 \pi 0$

$w_{1}=2355 \mathrm{cos} 02 \% .4 .800040$

$w 2=-3712000.244+15.00$

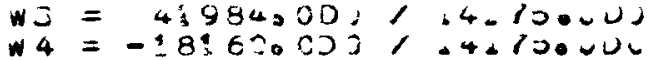

INITIALILE RLNVIVS SUMA TU L-NUD

FLAG $=0.00 C$

RESUL T $=0.300$

$C O R \perp i=0.000$

ERREST $=$ C.CDO

AREA

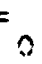

IF $(A, E \ddot{Q}, B)$ ZCTUKIN

$\stackrel{c}{c}$

$$
\text { If (A DEQ B) ZTURIN }
$$

*** STAGE $2 * * *$ IIVITIALILAI UN FUR FIKST INTERVAL

$$
\begin{aligned}
& \begin{array}{l}
\text { LEV }=? \\
N I M=i
\end{array} \\
& \begin{array}{l}
N I M= \\
X U
\end{array}=A \\
& x(\angle \hat{O})^{A}=y \\
& \text { UPREV }=3.200 \\
& F O=F U N(V I, X 0.5 L A L P H) \\
& \text { STUN }=(\Delta-4),- \text { U. UUU } \\
& x(y)=(x)+x(30) 1), \text { Lavou } \\
& x(4)=(x)+x(0),) \text { Lavu }
\end{aligned}
$$

$000 \mathrm{C} 280$

$000 C 0280$

00000300

00006310

$\cos 0320$

00003330

00000340

$000 \mathrm{CO} 350$

00000360

00000370

00000380

00000390

00000400

00000410

COOCC420

00000430

00000440

00000450

00060460

00000470

CCCC448

00590

0 CCC5O

O0OCO510

00000520

$000 ट 0530$

$0000 \mathrm{C} 540$

CO0OC550

$0000 C 560$

$\mathrm{COOCC570}$

00000580

00000590

$000 \mathrm{C} 060 \mathrm{C}$

00000610

COOCCE2O

00000630

00000640

DOOCCE5O

COOOC660

COOC C670

000 C68

C0000690

00000710

00000720

$0000 \mathrm{C} 730$ 
NOFUN $=9$

*** STAGE 3 *** vLIVTRAL LALLULATIUN

00000810

00000820

(1)

5000

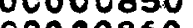

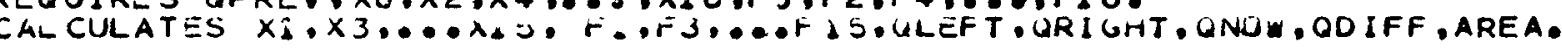

$30 \times(2)=(\times 0+x(2))$, Lo UUD

$F(i)=F U N(V I, X(1), C L A L P H)$

$0035 \mathrm{~J}=3,: 5,2$

$x(J)=(x(J-1)+x(J+A)), 20000$

35 C GNTINUE

NGFUN $=$ NOFUN +8

STEP $=(X(i 6)-X 0) / 10,01)$

$U L E F T=(W) *(F O+F(0))+w *(F(1)+F(7))+w 2 *(F(2)+F(E))$

$\dot{i}+3 *(F(3)+F(5))+* * r(4)) *$ JTEP

QRIGHT $(L E V+1)=(W 0 *(+(0)+F(\Delta 0))+W 1 *(F(g)+F(15) 1+* \angle *(F(10)+F(14))$

$+* 3 *(F(12)+F(x 3))+* 4 * F(A<)) * S T E P$

ONOW = OLEFT + QRIUHT(LËV+1)

$\triangle D I F F=$ QNOW - OPREV

$c$
$c$

*** STAGC 4 *** int-aval LuivVLrucince test

ESTERR = DAOS(OOIFR), J2J.JUC.

TOLERR = DMAXI(ABSEKM.RLLCRK\#UABS(AREA)) * (STCP/STUNE)

IF (LEV . LT. LEVMINI UU TJ 00

IF (LEV : GE: LEVMAX) GU TJ OL

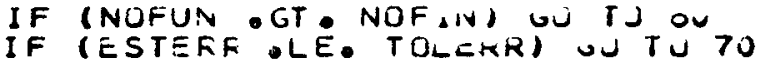

$c$
$c$
$c$
$C$

*** STAGE 5 **** Nu cuivVERUENCE

5o NIN $=2 * \Lambda I M$

$\stackrel{c}{c}$

STOFE RI UHT HAVO ELEME VTS FJA FUTURE UIE.

$0052 I=1=8$

FSAVE $(I, L E V)=F(i+8)$

52 CONTINUE

$A V E(1, L E V)=x(1+0)$

$c$
$c$

ASSEMBLE LEFT HAND ELIMENTS FUK IMMELIATIE USE.

QPREV = QLEFT
DO 50 I $=1.8$

$J=-I$

$F(2 * J+18)=F(J+y)$

55 CONT INUE

00000870

00000880

00000900

C0000910

00000930

C00CC940

CCCG 60

00000970

OCCC0980

C00C0990

.

C00021010

.

00010

0001050

000 cioso

$000 c 1060$

06501070

00001080

00061090

00002100

$000 c 1110$

00001120

00001130

00001140

00001150

CCOC1160

00001170

(1)

$000 C 1190$

COCC1210

00001220

00001230

30001240

00001250

c0001260

00001270

$000 c 1280$

00001290

00001310

$000 C 1320$

00001330 
60 NOFIN $=2 *$ NOF IN

LEVMAX = LEVOUT

$F L A G=F L A G+(B-X C) /(O-A)$

$\stackrel{c}{C}$ GO TO 70

CURRENT LEVEL IS LEVMAX.

62 FLAG $=$ FLAG + 1.00

C *** STAGE? *** LIVTEKVAL CONVERGËO

$\stackrel{c}{c}$

70 RESULT = RESULT + WNU ERREST $=$ ERREST + ESTERR

LOCATE NEXT INTERVAL.

72 IF (NIM EEQ. $2 *(N I M / \angle J)$ U TO 75

NIM $=N I M / 2$

LEV $=$ LEV $V$

GO TO 72

$75 N I M=N I M+1$

IF (LEV $L$ LE. $O)$ GO TU 80

C ASSEMBLE ELEMENTS REUU,RLU FJR THE MEXT INTERVAL.

QPREV = QRIGHT(LEV

$\times 0=x(16)$

$F O=F(16)$

DO $78 I=1.3$

$F(2 * 1)=F S A V E(I, L E V)$

78 CONTINUE

$X(2 * I)=X$ SAVE (1,LCV)

$\stackrel{c}{C}$

*** STAGE 8 *** FaNALILL AND RETURN

8. RESULT = RESULT + UURAL

$\stackrel{c}{c}$

MAKE SURE ERREST NOT LLSS THAN ROUNDOFF LEVEL.

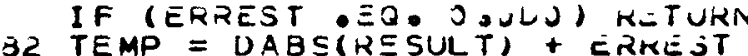

IF (TEMP ONE. OABS(RLSULT)) KLTUKN IF ITEMP ONE OOABSTRL GO TO 82

END

C FUN IS THE INTEGRAND

FUNCTI ON FUN( VI,OI, CLALPH)

DQUBLE PRECISION VI.UI.ELALPH, AA, BB, CC.FUN,EXP $A A=(O I-.72) * *(-.4 .9)$

oU $\left.=10 . * *(1-.909743) *\left(\omega_{0}-.72\right) * * .581\right)$ 


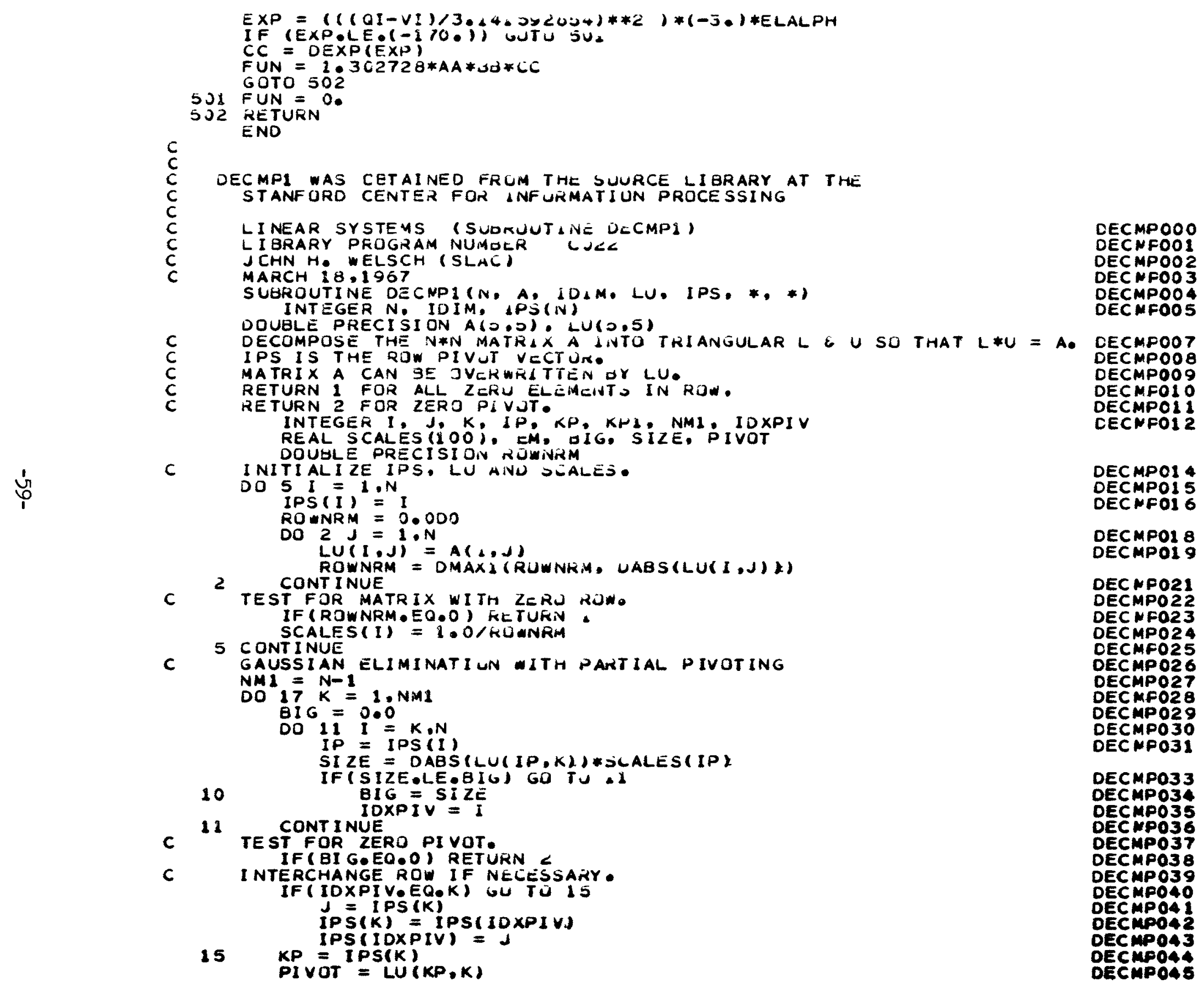




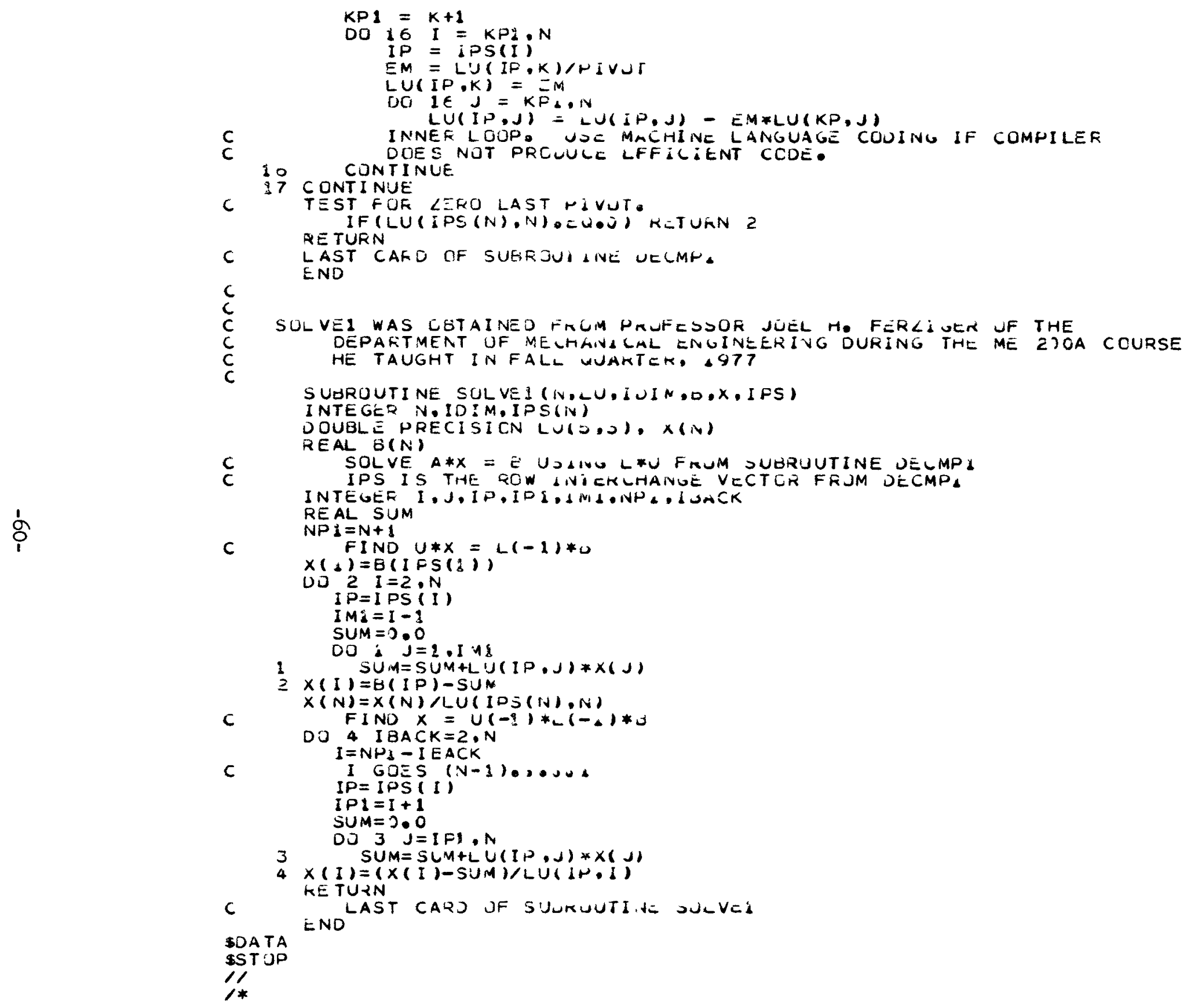

